\title{
Late-Successional and Old-Growth Forests in the Northeastern United States: Structure, Dynamics, and Prospects for Restoration
}

\author{
Mark J. Ducey ${ }^{1, *}$, John S. Gunn ${ }^{2,3}$ and Andrew A. Whitman ${ }^{3}$ \\ 1 Department of Natural Resources and the Environment, University of New Hampshire, \\ 114 James Hall, Durham, NH 03824, USA \\ 2 Spatial Informatics Group-Natural Assets Laboratory (SIG-NAL), 63 Marshall Pond Rd., Hebron, \\ ME 04238, USA; E-Mail: jgunn@sig-nal.org \\ 3 Natural Capital Initiative, Manomet Center for Conservation Sciences, 14 Maine St., Suite 410, \\ Brunswick, ME 04011,USA; E-Mail: awhitman@manomet.org \\ * Author to whom correspondence should be addressed; E-Mail: mark.ducey@unh.edu; \\ Tel.: +1-603-862-4429; Fax: +1-603-862-4976.
}

Received: 2 July 2013; in revised form: 9 November 2013 / Accepted: 14 November 2013 / Published: 26 November 2013

\begin{abstract}
Restoration of old-growth forest structure is an emerging silvicultural goal, especially in those regions where old-growth abundance falls below the historic range of variability. However, longitudinal studies of old-growth dynamics that can inform silvicultural and policy options are few. We analyzed the change in structure, including stand density, diameter distribution, and the abundance of large live, standing dead, and downed dead trees on 58 late-successional and old-growth plots in Maine, USA, and compared these to regional data from the U.S. Forest Inventory and Analysis program. Structural dynamics on the late-successional plots reflected orderly change associated with density-dependent growth and mortality, but dynamics on the old-growth plots were more variable. Some plots experienced heavy mortality associated with beech bark disease. Diameter distributions conformed poorly to a classic exponential distribution, and did not converge toward such a distribution at the plot scale. Although large live trees showed a broad trend of increasing density in regional forests, recent harvesting patterns offset a considerable fraction of those gains, while mean diameter was static and the number of large dead trees was weakly declining. Even though forests of the northeast are aging,
\end{abstract}


changes in silviculture and forest policy are necessary to accelerate restoration of old-growth structure.

Keywords: stand structure; coarse woody debris; snags; Weibull distribution; retention

\section{Introduction}

Old-growth forests provide a range of ecosystem services, including carbon storage (e.g., [1,2]), biodiversity elements [3], and recreational and amenity benefits [4]. Globally, the area of both primary and old-growth forests is declining [5-7]. However, in some areas old forests are believed to be increasing on the landscape. One of these is the northeastern United States, where forest area and age structure have generally been recovering following a history of agricultural clearing and extensive exploitation of remaining forests in the 19th century [8-10]. As a consequence of that land-use history, the age structure of forests in northeastern North America is likely much younger than that before extensive European settlement [11-14], but many anticipate a broad restoration of at least some late-successional and old-growth structure as those forests age in portions of the region (e.g., [15]). To the degree that late-successional and old-growth forests are underrepresented on the landscape, managing for the restoration of structures and services associated with those forests could be an important silvicultural goal [16,17].

Bauhus et al. [18] identify three main strategies for maintaining and increasing the representation of old-growth structure and services on the landscape: reservation, retention, and restoration. Reservation involves setting aside areas from harvest, which may be effective in preserving existing old-growth and providing opportunities for the development of younger forests into later-developmental stages, but this approach requires great patience and an awareness of the risks posed by disturbance. As such, it can be both land and capital-intensive. Retention involves the maintenance of some stands, or structural components within some stands, beyond what would be typical in business-as-usual silviculture. Restoration, by contrast, entails active attempts to foster structural attributes such as large live and dead trees, accelerate stand development, and increase structural diversity and complexity within the stand [16]. In the northeastern U.S., D'Amato and Catanzaro [19] emphasize a continuous spectrum of approaches for restoring old-growth structure, from passive to active management. Although restoration of structure does not necessarily restore all old-growth functions, we focus on it here as a definable, measurable characteristic of forests that is at least potentially amenable to management.

General structural patterns associated with temperate old-growth forests have been well-established in the existing literature (see [20] for a recent review). These include large quadratic mean diameter (QMD), increased abundance of large trees, and elevated amounts of standing and downed necromass in comparison to younger forests. These patterns have been corroborated for forests in the northeastern United States, and existing studies have provided an increasing number of "snapshots" of structural conditions in the remnant old-growth stands of the region or in compositionally similar areas elsewhere in North America (e.g., [21,22]). However, late-successional and old-growth forests are dynamic. For example, in the carbon context, there has long been a perception that old-growth forests 
approach a "steady state" in terms of their biogeochemistry and net atmospheric exchange [23,24], but more recent studies have suggested that old-growth forests may continue to serve as net carbon sinks for an extended period [2,25,26]. Conversely, other studies have emphasized the risk to old-growth structures and carbon storage from disturbances [27,28]. Nonetheless, most studies of old-growth structure in the northeastern United States are based on one-time measurements (e.g., [21,22,29,30]), reconstructions in combination with one-time measurements [31-33], or studies in which plots were located in the same general area but not in identical locations [34]. At first glance, the study by Filip et al. [35] might appear to be an exception, but the use of "old growth" in that study does not conform to modern definitions. Thus, in general, there is a need for studies that link structure to dynamics and underlying mechanisms [33], and analyses of data from remeasured plots (e.g., [36-39]) are rare and geographically sparse. Moreover, in the context of restoration, there is a need for more specific silvicultural targets and guidelines that reflect the likely dynamics and changes in these forests over time, including responses to disturbance.

The goals of this study are:

1. To quantify existing structure and structural change in a series of remeasured late-successional and old-growth forest plots from northern Maine, USA, with a focus on stocking levels, diameter distribution, and structural legacies including large live trees and standing and downed dead wood.

2. To put these intensively studied plots in a regional context (encompassing northern New England and New York), by examining the abundance, development, and harvesting patterns of late-successional and old-growth plots from the U.S. Forest Service, Forest Inventory and Analysis program.

3. To suggest both silvicultural strategies and policy directions to enhance the prospect for the restoration of late-successional and old-growth structures in forests of the northeastern United States.

\section{Experimental Section}

\subsection{Intensive Plot Data and Analysis}

Data used in this study come from a series of permanent plots established between 1995 and 2002 to evaluate the impacts of harvest regimes on forest structure across Maine, including partially harvested, late-successional (LS), and old-growth (OG) stands [40,41]. LS plots were established between 1998 and 2002, while OG plots were established in 1995. LS and OG stands were remeasured in 2011, with some LS plots excluded due to stand-replacing harvest disturbance. Plots were established in northern hardwood and spruce-fir stands. Northern hardwood plots were characterized by Fagus grandifolia (American beech), Acer saccharum (sugar maple), and Betula allegheniensis (yellow birch). Spruce-fir plots were characterized by Picea (predominantly Picea rubens, red spruce; with occasional P. glauca, white spruce) and Abies balsamea (balsam fir). Gunn et al. [42] report on the changes in aboveground carbon stocks; here, our focus is on structural change.

LS plots $(n=23)$ were located in Kibby and Skinner Townships, northern Franklin County, Maine (centered at $45^{\circ} 25^{\prime} \mathrm{N}$ and $70^{\circ} 31^{\prime} \mathrm{W}$ ) on privately-owned forestland that had 100 years of harvest 
history. Although these plots had field or documentary evidence of limited prior logging, they were classified as LS stands because they lacked evidence of natural or human stand-replacing disturbances based on field observations (e.g., tip-up mounds, fire scars), historical stand maps, logging records, and tree increment cores from the plots. Ages of canopy trees on these plots, based on sanded cookies taken from near ground level, ranged from 87 to 180 years with a mean age of 119 years (A. Whitman, unpublished data [43]).

OG plots $(n=35)$ were located in the Big Reed Forest Reserve, located in northern Piscataquis County, Maine (approximately $46^{\circ} 20^{\prime} \mathrm{N}$ and $69^{\circ} 5^{\prime} \mathrm{W}$ ), which is owned and managed by The Nature Conservancy. This 2000 ha reserve is one of the few extensive areas of old-growth forest in northern New England. These sites lacked any field or documentary evidence of past logging or other recent anthropogenic disturbance. Fraver et al. [44] found no evidence of stand replacing disturbance during the last 120-280 years on their plots at Big Reed, and our plots are located in close proximity. The high conservation value of these sites prevented direct estimation of tree ages on our plots, but previous authors have estimated a maximum tree age of approximately 200 years [45].

At both LS and OG sites, plot locations were chosen at random within polygons derived from stand maps, and field crews did not relocate plots to avoid gaps or patches of regeneration, or to attempt to include "exemplary" features such as large live or dead trees. All plots were 0.05 ha rectangular plots. Except for diameters of dead coarse woody material (DCWM), the original measurement methods (as described in $[41,42])$ were used at remeasurement. For standing trees, diameter at breast height (DBH) of all live and dead stems $(7.5 \mathrm{~cm}$ DBH or larger) was measured to the nearest $\mathrm{cm}$, and decay stage (using an 8-class system; [42]) was assigned for the entire tree if dead; for each piece of DCWM (10 $\mathrm{cm}$ or greater mid-point diameter, $30 \mathrm{~cm}$ or greater in length) length and mid-point diameter was measured and a decay stage (using a standard 5-class system; [42]) was assigned. At the initial measurement, DCWM diameters were measured using a linear tape measure held horizontally over the log. Calipers were used at the remeasurement. The initial measurement method may overestimate mid-point diameter compared to the remeasurement method, but the effects on estimated changes in DCWM abundance are likely small in comparison with sampling variability. Moreover, in 1995, the dimensions of the entire DCWM piece were recorded if any portion of it fell on the plot. Using the ordinary expansion factor (i.e., the reciprocal of plot area) to scale each piece to a per hectare value would lead to biased estimates under this protocol [46]. During remeasurement we measured both the full dimensions of each piece (e.g., the initial protocol) and the dimensions of the portion on the plot, but present the analysis using the full dimensions here for consistency. DCWM abundance and volume per ha was calculated from these data using unbiased expansion factors [42]. However, the field crew in 1995 appeared to have used different operational definitions for dealing with buried or concealed downed wood, and may have differed in search efficiency. Thus, the downed wood data for the OG stands at the initial measurement are not comparable to those on the OG stands upon remeasurement, or to the LS stands at either time [42]. Thus, we present the downed wood data only from 2011 for the OG stands here.

For each plot at each measurement period, we computed basic descriptors of stand structure including trees per hectare, basal area per hectare, and quadratic mean diameter. Following [3], we defined large trees as those with DBH $40 \mathrm{~cm}$ or greater, and calculated the density and basal area of large live and dead trees accordingly. To explore the dynamics of these stands graphically, we plotted 
their positions in the variable space defined by Reineke's [47] stand density index (SDI), i.e., the logarithm of live tree density and the logarithm of QMD. Reineke's SDI can be calculated simply as:

$$
S D I=N(Q M D / 25.4)^{1.6}
$$

where $N$ is the total number of trees per hectare in the stand, and $Q M D$ is quadratic mean diameter (cm). However, Reineke's SDI was originally developed for even-aged monocultures, not complex, mixed-species such as those in this study. To gain further insight into LS and OG stand dynamics, and to provide a measure of comparability to silvicultural guidance for conventional stands in the region, we calculated a species-weighted, additive relative density measure (SWARD) developed for northeastern forests [48]. Specifically,

$$
S W A R D=\sum_{i} T P H_{i}\left(0.00015+0.00218 S G_{i}\right)\left(D B H_{i} / 25\right)^{1.6}
$$

where the summation is over the trees on a plot or in a stand, $T P H_{i}$ is the number of trees per hectare represented by the ith tree, $S G_{i}$ is its wood specific gravity, and $D B H_{i}$ is its diameter at breast height. SWARD takes a value of 0 for a completely unstocked stand, and a value of 1 when stocking is comparable to normal density or A-line stocking (sensu [49]). Values exceeding 1 do occur in heavily stocked stands, while values of 0.5-0.6 approximate crown closure or B-line stocking for most stocking charts used in the northeastern United States [48].

We also examined diameter distribution and its change over time on the LS and OG plots. Following the pioneering work of Meyer [50,51], many studies have considered diameter distributions with a constant value of de Liocourt's [52] $q$ (or "quotient of dimunition") as a benchmark if not a hallmark of uneven-aged structure. Diameter distributions with a constant $q$ conform to the exponential distribution [50,53]. However, other studies have noted the tendency for both managed uneven-aged stands and old-growth stands to tend toward a rotated-sigmoid distribution [54,55], and Keeton [16] specifically suggests a rotated-sigmoid management target for northern hardwood stands in the region. After initial consideration of a range of candidate diameter distribution formulations, we chose to test the exponential, the Weibull [56], and the generalized gamma [57,58]. The Weibull is perhaps the most widely used distribution for modeling diameter distributions in forests, and includes the exponential as a special case. It can take on both classic "reverse-J" and unimodal distributions. The generalized gamma is yet more flexible, and includes the Weibull as a special case. It can take on additional shapes, including some rotated sigmoids. For consistency of notation, we express all diameter distributions in this study in terms of McDonald's [58] parameterization of the generalized gamma,

$$
G G(y ; a, b, p)=\frac{a y^{a p-1} e^{-(y / b)^{a}}}{b^{a p} \Gamma(p)}
$$

where $a, b$, and $p$ are parameters to be estimated, and $\Gamma(p)$ is the gamma function. The parameters $a$ and $p$ control the shape of the distribution, while $b$ is a scale parameter. In terms of this notation, the Weibull distribution is:

$$
W e i b(y ; a, b)=G G(y ; a, b, 1)=\frac{a y^{a-1} e^{-(y / b)^{a}}}{b^{a}}
$$

Note that the parameter $a$ here is identical with the shape parameter $c$ in Bailey and Dell (1973). The exponential distribution, in this parameterization, is: 


$$
\operatorname{Exp}(y ; b)=W e i b(y ; 1, b)=G G(y ; 1, b, 1)=\frac{e^{-(y / b)}}{b}
$$

If the LS and OG plots fit Meyer's [50] classic model of a "balanced" intimate mixture, then the exponential distribution should provide the best fit of the three distributions after appropriately accounting for parsimony. If the stands were converging toward that state, we might expect the Weibull or generalized gamma to provide a better fit, but with shape parameter (or shape parameters, in the generalized gamma case) converging over time toward 1. We fit all three distributions to the live tree diameters on each plot in each year by maximum likelihood, using left-truncation at $7.5 \mathrm{~cm}$ to reflect the minimum measurement diameter for the field data. Fitting was conducted using custom scripts written in MATLAB (Mathworks, Inc., Natick, MA, USA). Model fits were compared using Akaike's Information Criterion (AIC) $[59,60]$ to assess which distribution formula provided the best predictive model, both for individual plots and for LS and OG plots as a whole (using pooled AIC.values as appropriate).

\subsection{Regional Analysis}

To put the LS and OG plots in regional context, we used data from the U.S.D.A. Forest Service, Forest Inventory and Analysis (FIA) program. FIA is the national forest inventory for the United States, and includes plot data collected across all ownership types. FIA installs one plot, consisting of a cluster of four $7.33 \mathrm{~m}$ radius subplots, per approximately 2000 ha of forested land (trees between 2.54 and $12.7 \mathrm{~cm} \mathrm{DBH}$ are measured on nested microplots). The aggregate area of an FIA plot is comparable to that of the rectangular plots used in the LS and OG stands (Section 2.1). Plots are remeasured on a nominal five year interval and approximately $20 \%$ of plots remeasured in any given year. Full details of the FIA program and its procedures are given by [61].

We used data from Version 5 of the FIA database (FIADB), downloaded on 12 October 2012. We eliminated plots that were mapped as having mixed condition (e.g., a mixture of forest and nonforest conditions on the plots), as interpreting plot attributes from plots that may include "slivers" of forest condition as reflecting stand attributes is problematic. For this analysis, we included only remeasured plots north of $42^{\circ} 30^{\prime} \mathrm{N}$ and east of $76^{\circ} 30^{\prime} \mathrm{W}$, a study region that encompasses northern New York (including the Adirondacks, which contain some old-growth areas) as well as the northern New England states of Vermont, New Hampshire, and Maine, along with a limited area in the adjacent state of Massachusetts. FIA does perturb the plot locations in the FIADB by as much as a few kilometers to preserve plot integrity and landowner confidentiality but that has little impact on a regional scale analysis such as this one.

We used stand age as recorded in the FIADB at the last plot measurement (2007-2011, with a very small number of plots measured in 2012) to estimate a year of stand establishment. FIA uses a weighted average of three increment cores, typically read in the field, to estimate stand age. While this measure can be problematic, it provides the only consistent estimate of stand age distribution for the region. We calculated QMD and SWARD (using only trees $7.5 \mathrm{~cm}$ and larger DBH, for comparability with the LS and OG plots), as well as the number of large (40 $\mathrm{cm} \mathrm{DBH}$ and larger) live and dead trees per hectare. We separated the plots by broad ownership category (public vs. private), protection (unprotected vs. protected), and harvest status (those plots with harvested trees during the prior 5 year 
measurement interval, $v s$. those that did not). Because remeasurement intervals for a small number of plots deviated from the nominal 5 years, we rescaled all changes to a 5-year period for summarization and before conducting any statistical analyses. Statistical analyses included $t$-tests, chi-square tests, and analyses of variance and were conducted in the R statistical package [62].

\section{Results and Discussion}

\subsection{Intensive Study Plots}

General structural attributes of the LS and OG stands are summarized in Table 1. In terms of average species composition, the LS stands were dominated at the initial measurement by Acer saccharum (SWARD = 0.256), Abies balsamea (SWARD = 0.138), Betula papyrifera $(\mathrm{SWARD}=0.104)$, and Betula allegheniensis $(\mathrm{SWARD}=0.086)$, with other species contributing 0.122 to the SWARD of the average plot. This average composition remained quite stable through 2011 (SWARD =0.268, 0.144, 0.094, 0.090, and 0.126 for Acer saccharum, Abies balsamea, Betula papyrifera, Betula allegheniensis, and other species, respectively). By contrast, species composition of the OG stands showed greater change. At the initial measurement, OG stands were dominated by Acer saccharum (SWARD =0.251), Fagus grandifolia (SWARD $=0.143$ ), Picea rubens $(\mathrm{SWARD}=0.128)$, and Abies balsamea (SWARD $=0.069)$, with other species contributing 0.126 to SWARD. But by 2011, Fagus grandifolia and Picea rubens had switched position, with contributions to SWARD of $0.236,0.116,0.077,0.051$, and 0.145 by Acer saccharum, Picea rubens, Fagus grandifolia, Abies balsamea, and other species respectively. The reduction of Fagus in the OG stands was accompanied by a loss of basal area and a reduction in average stocking levels as measured by total SWARD, while these both increased slightly in the LS stands.

Table 1. General structural attributes of late-successional (LS) and old-growth (OG) stands.

\begin{tabular}{|c|c|c|c|c|c|c|c|c|c|c|c|c|c|}
\hline \multirow{2}{*}{$\begin{array}{c}\text { Stand } \\
\text { Type } \\
\end{array}$} & \multirow{2}{*}{ Period } & \multicolumn{3}{|c|}{ Basal Area, $\mathbf{m}^{2} / \mathrm{ha}$} & \multicolumn{3}{|c|}{ Trees/ha } & \multicolumn{3}{|c|}{ QMD, cm } & \multicolumn{3}{|c|}{ SWARD } \\
\hline & & Mean & Min & Max & Mean & Min & Max & Mean & Min & Max & Mean & Min & Max \\
\hline \multirow{2}{*}{ LS } & In & 30.2 & 20.8 & 42.7 & 923 & 320 & 1,980 & 22.2 & 14.6 & 34.0 & 0.706 & 0.437 & 0.947 \\
\hline & & 31.8 & 22.4 & 54 & 83 & 360 & 2,240 & 23 & 15.3 & 34.5 & 0.721 & 0.536 & 1.034 \\
\hline \multirow{2}{*}{ OG } & Initial & 33.8 & 21.7 & 54.5 & 661 & 360 & 1,020 & 25.9 & 19.9 & 36.8 & 0.718 & 0.354 & 1.167 \\
\hline & 2011 & 30.6 & 16.6 & 49.9 & 596 & 340 & 880 & 25.8 & 18.1 & 35.9 & 0.635 & 0.405 & 1.026 \\
\hline
\end{tabular}

The results in Table 1 are broadly comparable with those from studies of stands with similar composition from northern North America as tabulated in [20]. For example, McGee et al. [30] report basal areas from 29.1 to 33.7 and QMD from 27.0 to $33.1 \mathrm{~cm}$ in old-growth hardwood stands in New York, Beaudet et al. [63] report a basal area of $29.9 \mathrm{~m}^{2} /$ ha and QMD of $31.6 \mathrm{~cm}$ in old-growth Acer saccharum-Fagus grandifolia forests in Quebec, Keeton et al. [64] report basal areas from 24.0 to $33.0 \mathrm{~m}^{2} /$ ha and QMD from 19.8 to $20.5 \mathrm{~cm}$ in riparian mature and old-growth forests in New York, and Hoover et al. [65] report basal areas from 21.1 to $45.1 \mathrm{~m}^{2} /$ ha and QMD from 14.2 to 31.0 in twelve hardwood-dominated old-growth stands in Vermont, New Hampshire, and Maine.

The average abundance of large live trees, large standing dead, and large downed dead material is shown in Table 2. The OG stands did show elevated abundance of large live trees in comparison to the 
LS stands, but the patterns for standing and downed dead are less clear due to between-plot and intertemporal variability. Table 2 reflects the large living tree size thresholds used by Whitman and Hagan [3]. Recalculation of large live tree density using the more conservative $50 \mathrm{~cm}$ threshold used by Burrascano et al. [20] yields results that are similar to some of the results in their tabulation. In 2011, the LS stands had $10.4 \pm 2.4$ trees/ha greater than $50 \mathrm{~cm} \mathrm{DBH,} \mathrm{while} \mathrm{the} \mathrm{OG} \mathrm{stands} \mathrm{had}$ $33.7 \pm 9.5$ (densities at the first measurement were not statistically different). By comparison, [64] report large live tree densities (50 cm and larger) of 11-12 trees/ha in mature and 37 trees/ha in old-growth Adirondack stands, while [30] report 17 and 65 trees/ha in mature and old-growth forests in the same region, respectively. Although separated geographically by hundreds of $\mathrm{km}$, and slightly different in species composition and site characteristics, these similarities do suggest compatibility across the region in setting broad structural targets for restoration.

Table 2. Structural legacies, including density and basal area $\left(\mathrm{m}^{2} / \mathrm{ha}\right)$, large live and standing dead trees $(\geq 40 \mathrm{~cm} \mathrm{DBH})$, as well as density and volume $\left(\mathrm{m}^{3} / \mathrm{ha}\right)$ of large downed dead wood ( $\geq 40 \mathrm{~cm}$ midpoint diameter), in late-successional (LS) and old-growth (OG) stands. Results are shown as mean \pm 1 standard error.

\begin{tabular}{cccccccc}
\hline & & \multicolumn{2}{c}{ Large Live Trees } & \multicolumn{2}{c}{ Large Standing Dead } & \multicolumn{2}{c}{ Large Downed Dead } \\
\hline Stand Type & Period & Trees/ha & Basal Area & Trees/ha & Basal Area & Pieces/ha & Volume \\
\hline LS & Initial & $29.6 \pm 8.2$ & $5.4 \pm 1.6$ & $1.7 \pm 1.2$ & $0.3 \pm 0.2$ & $7.3 \pm 1.7$ & $12.1 \pm 3.3$ \\
& 2011 & $38.3 \pm 9.1$ & $6.8 \pm 1.8$ & $3.5 \pm 2.0$ & $0.6 \pm 0.3$ & $7.6 \pm 1.6$ & $11.5 \pm 4.1$ \\
OG & Initial & $66.3 \pm 6.1$ & $13.7 \pm 1.4$ & $4.0 \pm 1.6$ & $0.8 \pm 0.3$ & - & - \\
& 2011 & $72.6 \pm 5.9$ & $15.3 \pm 1.3$ & $2.3 \pm 1.4$ & $0.5 \pm 0.3$ & $10.7 \pm 2.0$ & $18.0 \pm 3.4$ \\
\hline
\end{tabular}

Although the results in Tables 1 and 2 suggest limited changes in the LS and OG stands, it should be remembered that these are average conditions: individual plots showed distinct dynamics, and these are informative for understanding both restoration approaches and challenges. This can be seen quite clearly in the trajectories of the stands through the variable space that defines Reineke's [47] Stand Density Index (SDI) (Figure 1). This variable space has been used successfully to develop a model of stand growth, mortality, and ingrowth in the Acadian forest just across the Canadian border from our study region [66]. The LS plots commonly show the expected trajectory for stands undergoing self-thinning in the stem exclusion stage of Oliver and Larson [67], moving nearly parallel to the maximum SDI as the stands increase in QMD and decline in trees/ha. However, no overriding pattern can be seen in the OG plots, which appear almost random in the direction and magnitude of their motion in Reineke space. In a sense, this is consistent both with the Oliver and Larson [67] and Franklin et al. [68] stand development models, which both predict a transition away from self-thinning toward other modes of mortality as stands reach advanced developmental stages. One would expect that patchy, density-independent mortality would create a random pattern, especially at the spatial scale of conventional fixed-area plots such as those used in this study ( 0.05 ha). At a larger scale, such localized disturbances might "average out" to create a more stable pattern of structural change, especially if disturbances were asynchronous throughout a stand (e.g., treefall gaps occurring in different areas of the stand in different decades). Alternatively, if such gaps were created by large regional disturbances (e.g., ice storms, major wind events), the result might be a punctuated, irregular 
trajectory. The spatial scale of the field methods in this study does not allow us to address these alternative scenarios. However, we also note that the OG stands appear to have suffered particularly heavy impacts from beech bark disease, a result of sap feeding by an introduced beech scale insect (Cryptococcus fagisuga) that facilitates potentially lethal fungal infections by Neonectria ditissima and Neonectria faginata. Beech bark disease reached the OG study area between 1935 and 1945 [69]. However, an episode of high Fagus mortality associated with a combination of drought and beech bark disease occurred in northern Maine (including the OG study area) from 2003-2006 [70], and live tree volume of Fagus has declined 14\% since 2003 [71]. Large diameter trees often experience greater decline and mortality from beech bark disease [69], so the OG study area may have been especially sensitive to this stressor.

Figure 1. Trajectories of the late-successional (LS) and old-growth (OG) stands in Reineke space, with open symbols indicating position at the initial measurement, and solid symbols indicating position in 2011. A dashed line at constant stand density index of 1137 , the maximum observed on any LS or OG plot, is shown for reference.
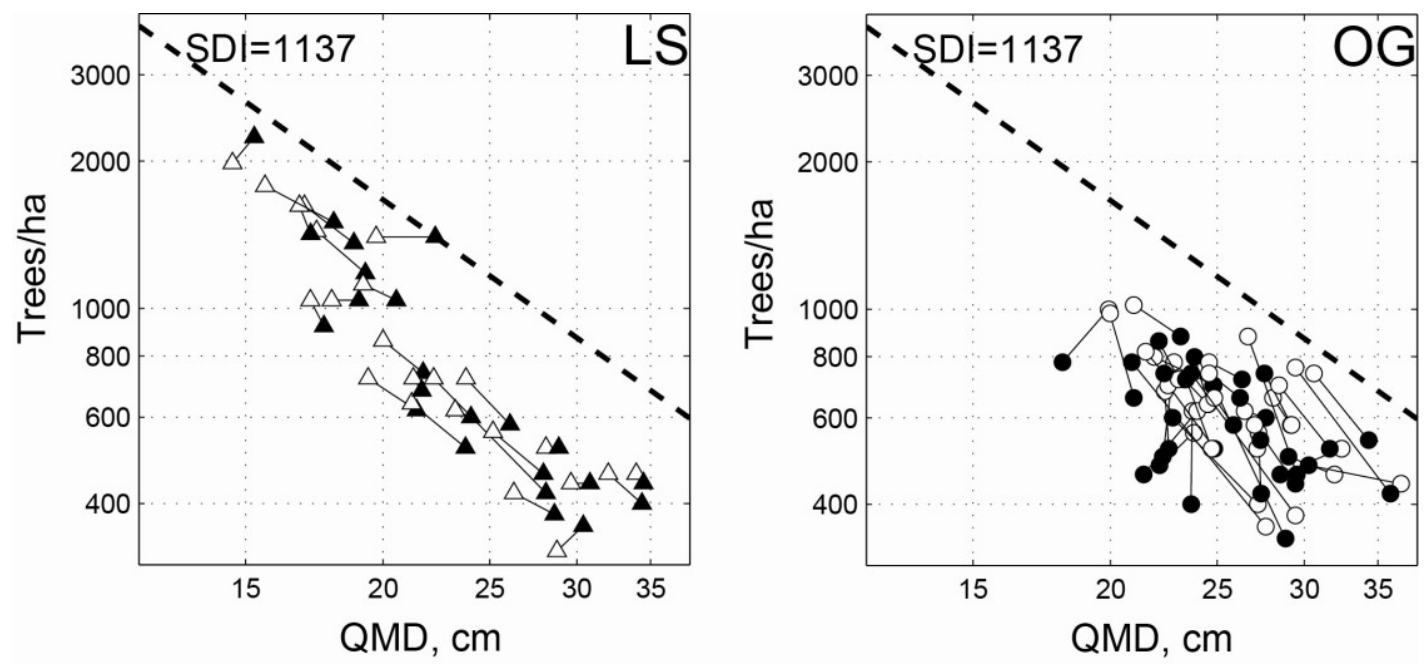

Although Reineke space is useful for visualizing overall change, Reineke's [47] SDI was originally developed for even-aged monocultures with simple structure, while SWARD accounts for species composition and diameter distribution [48], and has been shown to improve models of dynamics in the Acadian forest [66]. Examining the individual plot changes in SWARD, we also find substantial variability. On the LS plots, change in SWARD on an annualized basis ranged from -0.010 to +0.015 , while on the OG plots changes ranged from -0.021 to +0.010 (Figure 2). Although these annualized changes may seem small, over a period of a decade or more these rates of change would lead to changes in SWARD on the order of 0.1 to 0.2 in either direction, when SWARD itself averages approximately 0.6 to 0.7 . To better understand the patterns of change, we fit an initial regression model predicting annualized change in SWARD based on LS vs. OG, initial SWARD, initial SWARD in Fagus (due to the potential impact of beech bark disease), and initial QMD as predictors, then eliminated predictors sequentially to minimize AIC. The final predictive model was: 
$\triangle S W A R D=0.0096( \pm 0.0042)-0.0126( \pm 0.0060) S W A R D_{\text {total }}-0.0373( \pm 0.0080) S W A R D_{\text {beech }}$ with $R^{2}=0.36$. (Although model selection was information-theoretic, for those readers who would prefer frequentist inference we note that the overall model, the intercept, and all coefficients would have been statistically significant with $p \leq 0.05$, and none of the terms excluded from the final model was statistically significant in any preliminary model.) The positive intercept and negative coefficient on total SWARD is expected, as indeed taking these two terms in isolation implies a dynamic model of stand structural development tending toward an asymptotic total SWARD of 0.0096/0.0126 $=0.76$. However, bootstrapping the original data indicates that the asymptote is very poorly constrained by these data, with $95 \%$ confidence limits from 0.58 to 1.36 . Of more interest is the coefficient on Fagus SWARD, which highlights again the role of beech bark disease in driving structural change in these forests.

Figure 2. Histogram of annual changes in species-weighted additive relative density (SWARD; [48]) for the late-successional (LS) and old-growth (OG) plots.
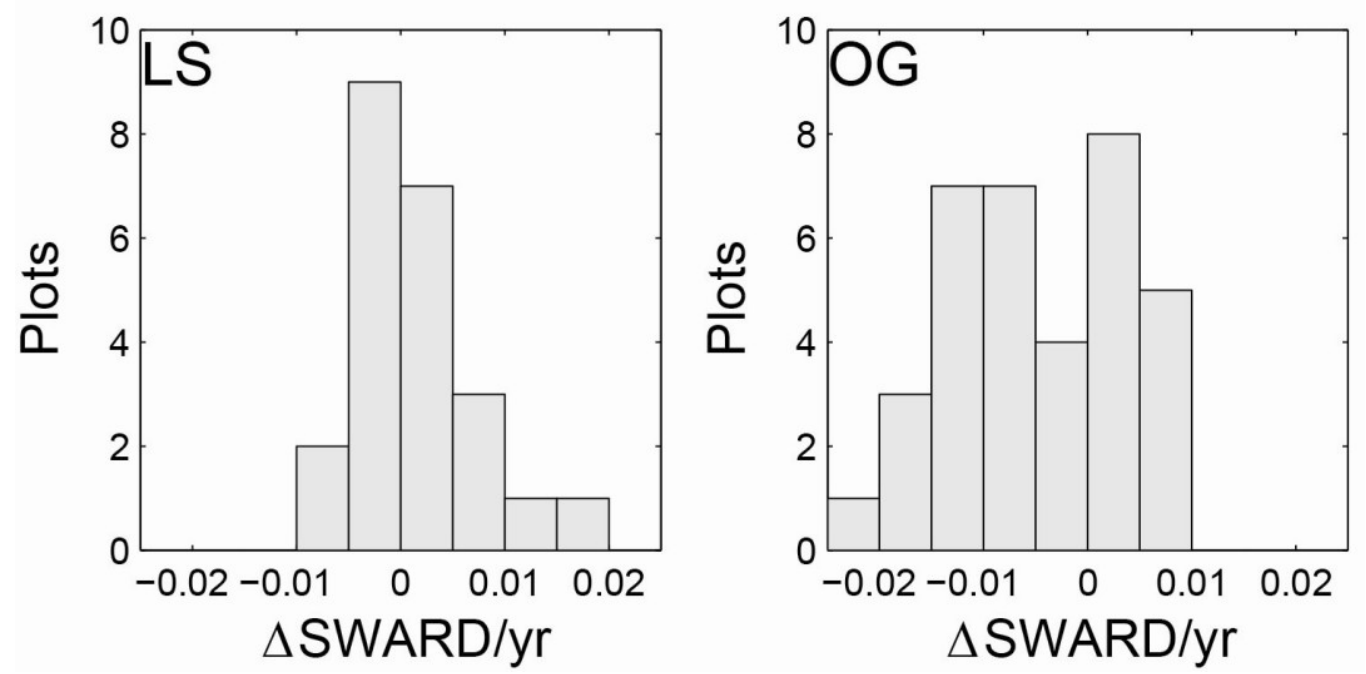

Diameter distributions at the individual plot scale, as well as their dynamics, were also highly variable. Table 3 provides a cross-tabulation, by initial vs. 2011 measurement, of the best-fitting distribution (exponential, Weibull, or generalized gamma) for each plot. Once again, the LS plots showed more stable patterns. The most common distribution on the LS plots was the Weibull, and these often had shape parameters greater than 1, indicating a unimodal distribution. Although some plots were best fit by different distributions at different time periods, for the majority (16 of 23) the best-fitting distribution at the initial measurement was also the best-fitting distribution in 2011. By contrast, the most common distribution for the OG plots at their original measurement was the exponential; but by remeasurement a substantial number of these plots had shifted to the Weibull. Examples of the most common patterns are shown in Figure 3. 
Table 3. Number of late-successional (LS) and old-growth (OG) plots, at initial measurement and in 2011, that were best fit by the exponential (Exp), Weibull (Weib), and generalized gamma (GG) distributions, with model fit evaluated by AIC.

\begin{tabular}{cccccc|cccccc}
\hline LS & & & 2011 & & OG & \multicolumn{3}{c}{ 2011 } \\
\hline & & Exp & Weib & GG & Total & & & Exp & Weib & GG & Total \\
\hline \multirow{4}{*}{ Initial } & Exp & 0 & 1 & 3 & 4 & & Exp & 13 & 10 & 1 & 24 \\
& Weib & 1 & 11 & 1 & 13 & Initial & Weib & 1 & 1 & 2 & 4 \\
& GG & 0 & 1 & 5 & 6 & & GG & 3 & 3 & 1 & 7 \\
& Total & 1 & 13 & 9 & 23 & & Total & 17 & 14 & 4 & 35 \\
\hline
\end{tabular}

Figure 3. Examples of diameter distribution change in a late-successional plot (46313) and two old-growth plots (BRSH14 and BRSH35): Weibull remaining Weibull (46313), exponential remaining exponential (BRSH14), and exponential shifting to Weibull with shape parameter $<1$ (BRSH35).
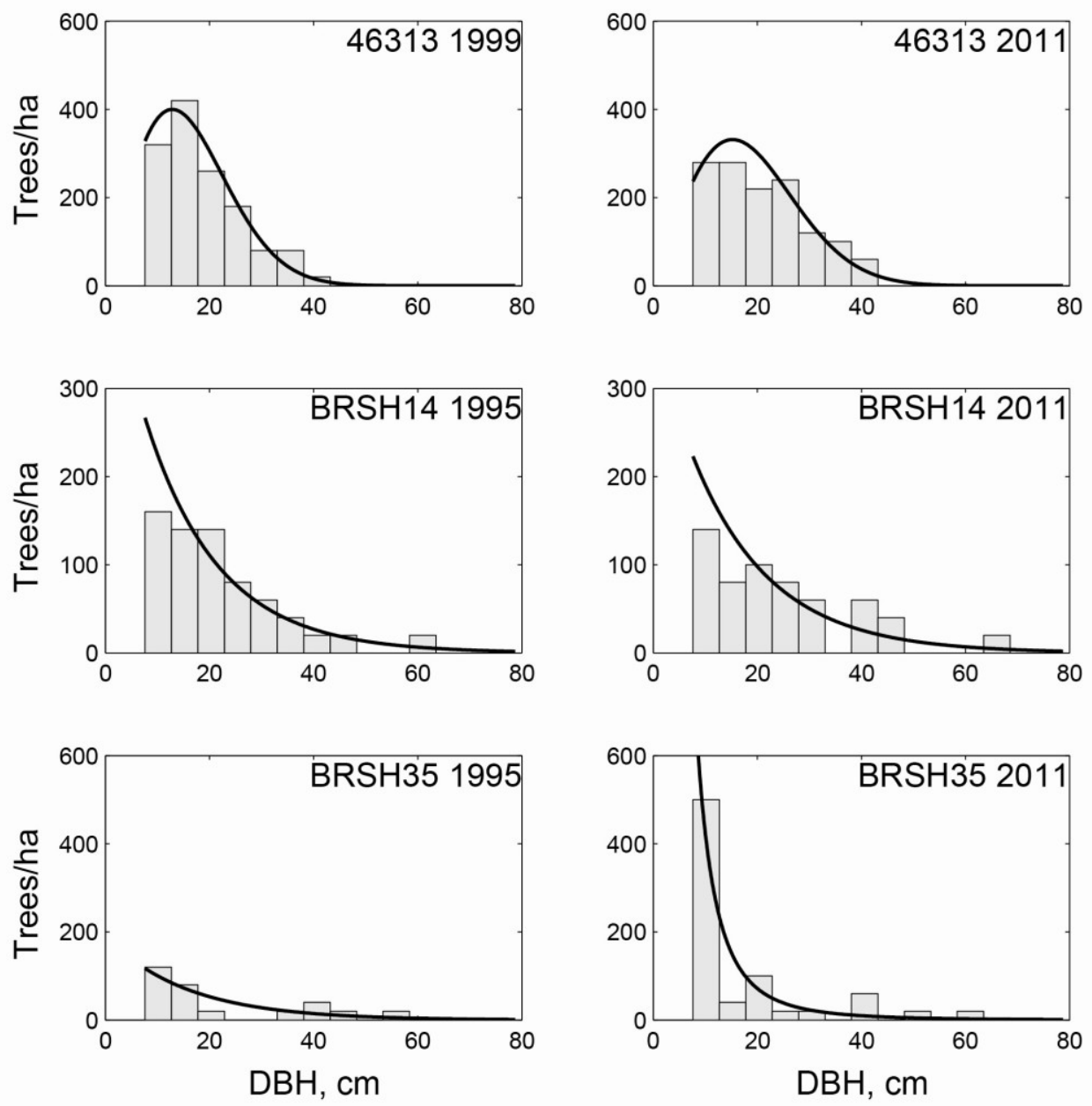
Pooling the results across plots allows evaluation of which diameter distribution form provides the best compromise between fit and parsimony across the LS and OG plots collectively. Looking at the LSOG plots as a whole, the Weibull provides the best balance of flexibility and parsimony, with the generalized gamma second $(\triangle \mathrm{AIC}=22.8)$ and the exponential far behind $(\triangle \mathrm{AIC}=291.5)$. In comparison with the Weibull, the other models have essentially no support ( $\triangle \mathrm{AIC}>10)$ [60]. Looking only at the LS plots, the best-performing model overall is the generalized gamma, followed by the Weibull $(\triangle \mathrm{AIC}=11.6)$, with the exponential a distant last $(\triangle \mathrm{AIC}=291.5)$. Although the generalized gamma is the "winner" for a definite minority of the LS plots, its flexibility is needed to describe the behavior of LS plots as a whole. By contrast, examining only the OG plots, the best-performing model is the Weibull, followed by the exponential $(\triangle \mathrm{AIC}=3.51)$ and the generalized gamma $(\triangle \mathrm{AIC}=22.8171)$. Even for the OG plots, the additional flexibility of the Weibull is needed to capture the observed structures.

Taking the Weibull as a base model, then, we can ask whether the LS and OG stands appear to be converging toward an exponential as time passes, even if the exponential is not the best fit at any given time, by examining changes in the shape parameter $a$ to see if it is moving closer to 1 . The results are shown graphically in Figure 4. Among the $23 \mathrm{LS}$ stands, 21 had unimodal distributions with $a>1$ at the initial measurement, and of these 13 had diverged farther from 1 by 2011 . Among the 35 OG stands, the dynamics were more complicated. There were 25 stands with $a>1$ at the outset, and of these 5 did converge closer to 1, while 6 diverged and 14 crossed over to $a<1$ (as with stand BRSH14 in Figure 2). Among the $10 \mathrm{OG}$ stands that began with $a<1,9$ diverged and 1 crossed. There is no evidence supporting a simple convergence of stands toward an exponential distribution over time. Indeed, if we use

$$
d=\frac{1}{n} \sum_{i}\left|a_{i}-1\right|
$$

as a robust metric of the departure of the plots from the exponential condition $a=1$, the plots actually diverged slightly overall ( $d=0.59$ at the initial measurement, and $d=0.66$ in 2011). The same qualitative result is reached if one substitutes squared difference for absolute difference in the formula for $d$. In summary, therefore, while a considerable number of the OG plots did conform reasonably well to the exponential model at the initial measurement, even for the OG plots the flexibility of the Weibull was needed to describe the range of diameter distributions, and neither the LS nor the OG stands are converging toward an exponential distribution over time, at least not at the plot scale.

\subsection{Regional Analysis}

The regional distribution of stand age, based on FIA data from 2007-2012, is shown in Figure 5. Of 3289 plots in the study region, only 17 (approximately $0.5 \%$ ) are 150 years old or older; 299 plots (approximately 9.1\%) are 100 years old or older. However, just over 30\% have a stand age between 75 and 99 years, and the median stand age is 68, suggestive of a demographic wave that is about to crest into the LS and OG condition. The spatial distribution of plots by age class within the study region is shown in Figure 6. 
Figure 4. Change in the shape parameter $a$ of the Weibull distribution for late-successional (LS) and old-growth (OG) plots; the special case of the exponential distribution $(a=1)$ is shown as a dashed line for reference.
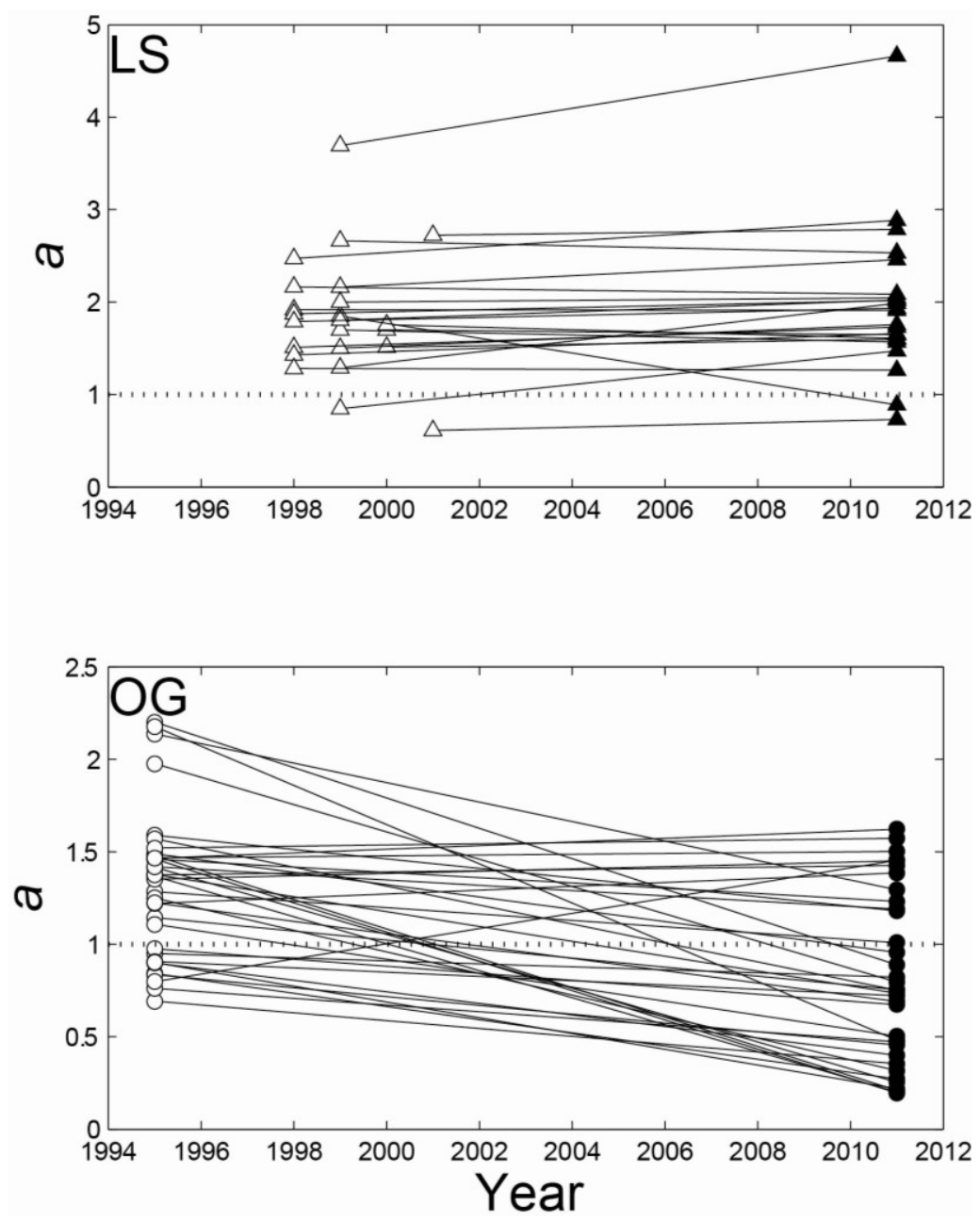

Figure 5. Regional age-class distribution of stand age in the U.S. Forest Inventory and Analysis (FIA) plot data.

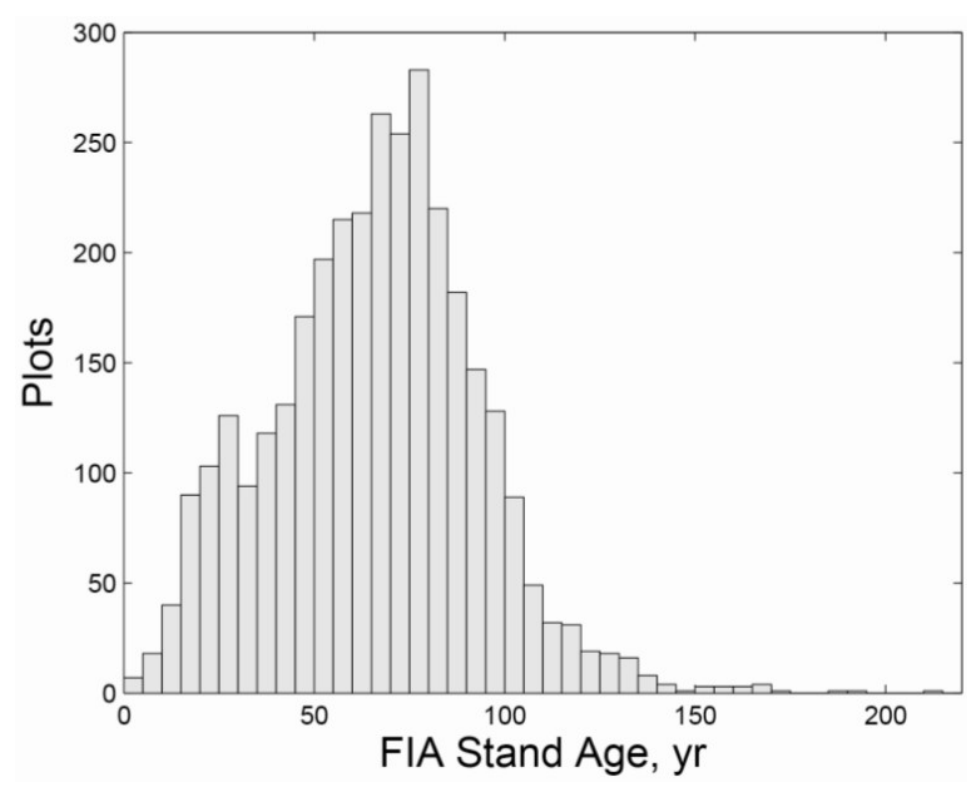


Figure 6. Spatial distribution of FIA plots by age class within the study region.

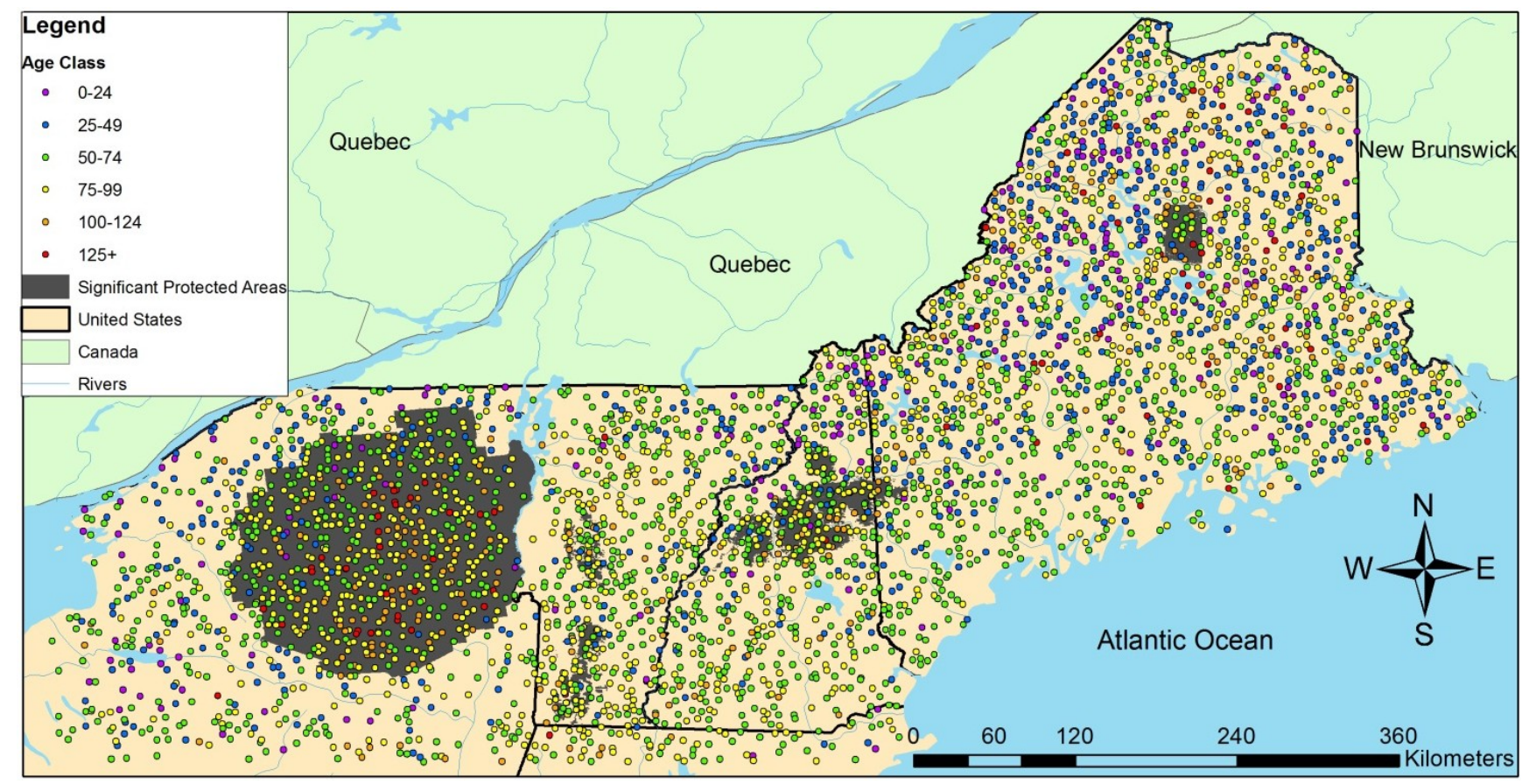

Broadly speaking, the structural attributes of the 100 year and older plots in the FIA data, as shown in Table 4, are comparable to those of the LS plots in this study. For example, the mean QMD of the older FIA plots is $22.9 \mathrm{~cm}$, as compared to $23.1 \mathrm{~cm}$ for the LS stands in 2011; the older FIA plots have 40.9 large live trees/ha vs. 38.3 on the LS plots, and average SWARD is 0.69 vs. 0.71 . We note that it is critical for comparability that these values are calculated using the same minimum diameter: both QMD and SWARD would have been very sensitive to inclusion of trees $<7.5 \mathrm{~cm}$ in the FIA data (FIA measures trees down to $2.54 \mathrm{~cm}$ ). For example, mean QMD on the older FIA plots would have been $15.3 \mathrm{~cm}$ and mean SWARD would have been 0.79 with the inclusion of trees between 2.54 and $7.5 \mathrm{~cm}$. Notably, the older FIA plots have over twice the density of large standing dead trees as the LS and OG plots in this study on average, and even the younger FIA plots appear to have considerable large standing dead stocks in comparison to these particular LS and OG plots. The reasons for this unexpected result are not entirely clear.

A major factor driving changes in regional LS structure is harvesting [72], which is tied to ownership. Previous analyses of remotely sensed data for the northeastern U.S. have indicated publically-owned forests tend to have higher biomass, and to be less fragmented by development and harvesting, than privately-owned forests on average [73]. However, nearly $90 \%$ of the study region is privately held [8,73]. Of the 261 FIA plots with stand age 100 or greater, 234 are on private land, vs. only 27 on public land. Of the plots on private land, 60 are on lands designated by FIA as "protected", indicating some legal or ownership prohibition against harvesting, while 11 of the plots on public land are in areas protected from harvest (the fraction of plots in protected status is not significantly different by ownership; Fisher's exact test, $p=0.29$ ). On private, unprotected lands, 35 of 179 plots were harvested; on public unprotected lands, 2 of 16. With so few older plots in unprotected public land, it is not surprising that one cannot statistically distinguish a difference in harvesting rate between ownerships in older plots alone (Fisher's exact test, $p=0.75$ ); but harvesting rates on unprotected 
lands overall were not significantly different $(16.2 \%$ of plots on private unprotected land $v s .13 .2 \%$ on public unprotected land, Fisher's exact test, $p=0.26$ ). In this study region, there has been a substantial shift toward partial harvesting [71,72], and this is reflected in the proportion of initial SWARD lost on plots that did experience harvest (reduction of 0.165 from an initial average stocking of 0.625 , or $26 \%$ ).

When we examine rates of change in these structural metrics, QMD was essentially static for the region as a whole, showing change within sampling error for most subcategories, but clearly showing a negative trend for harvested stands on private land (on both young plots and those 100 years and older, but the trend is most pronounced on the older plots). These changes are consistent with a pattern of partial harvesting that emphasizes the removal of larger trees, despite regional markets for smaller material [74]. The harvest of an older plot on private land, on average, reduced QMD from nearly $23 \mathrm{~cm}$ down to $20 \mathrm{~cm}$, which is closer to structure of young stands on average than to unharvested old stands. However, there also appeared to be slight losses in QMD in private, unharvested forests. We speculate that these losses are associated with beech bark disease, as on the OG plots in the intensive study [69,71]. There is less evidence for comparable changes on publically owned forests, but the sample size is extremely limiting for quantitative inferences. Overall, however, QMD is actually declining in old forests in the region, while young forests as a whole showed little or no gain, contrary to what would be expected from a naive look at the stand age distribution.

Rates of change for large live trees suggest a rosier picture: density change was positive everywhere except harvested stands. The rate of loss in harvested stands did offset a considerable fraction of the gains on unprotected lands, but the trend across the land base was still positive. A similar trend is reflected in SWARD: forests of the region, both young and old, are slowly becoming more densely stocked on average. However, densities of large snags are simply too variable to say anything with statistical confidence except for region as a whole, which has experienced a very slight decline. We speculate that this relates to the fall of snags created during a regional spruce budworm (Choristoneura fumiferana (Clem.)) outbreak that came to a close approximately two decades before the current study period.

Taken together, these patterns of harvesting and structural dynamics suggest flaws in the simple narrative of a middle-aged forest easing gently and predictably into its golden years. Although numbers of large live trees are increasing, other metrics of old-growth structure are not when considering the land base overall. Old-growth metrics and rates of change are generally positive in the protected portion of the land base, but elsewhere the pattern is ambiguous. 
Table 4. Key structural measures and their change (mean plus or minus one standard error) by ownership, protection status, and harvest. Initial refers to the 2003-2007 time period, while change is for a five-year interval (nominally through 2008-2012). Number of plots used for large standing dead (shown in parentheses) is lower due to protocol changes; only plots with valid initial and repeated measurement are used in the analysis.

\begin{tabular}{|c|c|c|c|c|c|c|c|c|c|c|c|c|}
\hline \multirow{2}{*}{ Ownership } & \multirow{2}{*}{ Protection } & \multirow{2}{*}{ Harvested } & \multirow{2}{*}{$\begin{array}{c}\text { Initial } \\
\text { Age }\end{array}$} & \multirow{2}{*}{$n$} & \multicolumn{2}{|c|}{ QMD (cm) } & \multicolumn{2}{|c|}{ Large Live Trees/ha } & \multicolumn{2}{|c|}{ Large Standing Dead/ha } & \multicolumn{2}{|c|}{ SWARD } \\
\hline & & & & & Initial & Change & Initial & Change & Initial & Change & Initial & Change \\
\hline \multirow{10}{*}{ Private } & \multirow{7}{*}{ Unprotected } & \multirow{2}{*}{ No } & $<100$ & $2127(1505)$ & $18.5 \pm 0.1$ & $0.20 \pm 0.06$ & $16.5 \pm 0.5$ & $3.1 \pm 0.2$ & $2.2 \pm 0.2$ & $-0.27 \pm 0.14$ & $0.54 \pm 0.01$ & $0.061 \pm 0.002$ \\
\hline & & & $100+$ & $139(97)$ & $21.6 \pm 0.4$ & $-0.21 \pm 0.20$ & $32.1 \pm 2.8$ & $5.0 \pm 0.9$ & $5.4 \pm 1.1$ & $-1.06 \pm 0.86$ & $0.68 \pm 0.02$ & $0.037 \pm 0.005$ \\
\hline & & \multirow{2}{*}{ Yes } & $<100$ & $406(285)$ & $19.6 \pm 0.2$ & $-0.87 \pm 0.23$ & $20.4 \pm 1.3$ & $-5.2 \pm 0.9$ & $2.2 \pm 0.4$ & $-0.68 \pm 0.29$ & $0.63 \pm 0.01$ & $-0.165 \pm 0.010$ \\
\hline & & & $100+$ & $35(23)$ & $22.7 \pm 0.8$ & $-2.73 \pm 1.00$ & $31.0 \pm 6.0$ & $-12.1 \pm 3.4$ & $5.2 \pm 2.0$ & $-0.86 \pm 1.64$ & $0.63 \pm 0.04$ & $-0.208 \pm 0.032$ \\
\hline & & \multirow{3}{*}{ All } & $<100$ & $2533(1790)$ & $18.7 \pm 0.1$ & $0.03 \pm 0.07$ & $17.1 \pm 0.5$ & $1.7 \pm 0.2$ & $2.2 \pm 0.2$ & $-0.34 \pm 0.12$ & $0.56 \pm 0.01$ & $0.025 \pm 0.003$ \\
\hline & & & $100+$ & $174(120)$ & $21.9 \pm 0.4$ & $-0.71 \pm 0.27$ & $31.9 \pm 2.5$ & $1.6 \pm 1.1$ & $5.3 \pm 0.9$ & $-1.02 \pm 0.76$ & $0.67 \pm 0.02$ & $-0.012 \pm 0.011$ \\
\hline & & & All & 2707 (1910) & $18.9 \pm 0.1$ & $-0.02 \pm 0.06$ & $18.0 \pm 0.5$ & $1.7 \pm 0.2$ & $2.4 \pm 0.2$ & $-0.38 \pm 0.13$ & $0.56 \pm 0.01$ & $0.023 \pm 0.003$ \\
\hline & \multirow{3}{*}{ Protected } & \multirow{3}{*}{ No (All) } & $<100$ & $174(103)$ & $20.7 \pm 0.4$ & $0.05 \pm 0.17$ & $33.3 \pm 2.4$ & $3.0 \pm 0.8$ & $7.7 \pm 1.3$ & $-1.84 \pm 0.72$ & $0.71 \pm 0.02$ & $0.018 \pm 0.006$ \\
\hline & & & $100+$ & $60(41)$ & $25.9 \pm 0.7$ & $-0.63 \pm 0.36$ & $63.7 \pm 4.8$ & $3.8 \pm 1.6$ & $15.2 \pm 2.5$ & $-0.38 \pm 1.54$ & $0.72 \pm 0.02$ & $0.029 \pm 0.009$ \\
\hline & & & All & $234(144)$ & $22.1 \pm 0.4$ & $-0.12 \pm 0.16$ & $41.1 \pm 2.3$ & $3.2 \pm 0.7$ & $9.8 \pm 1.2$ & $-1.42 \pm 0.68$ & $0.71 \pm 0.01$ & $0.021 \pm 0.005$ \\
\hline \multirow{10}{*}{ Public } & \multirow{7}{*}{ Unprotected } & \multirow{2}{*}{ No } & $<100$ & $262(187)$ & $19.1 \pm 0.4$ & $0.29 \pm 0.21$ & $20.8 \pm 1.9$ & $3.4 \pm 0.6$ & $2.7 \pm 0.6$ & $0.49 \pm 0.38$ & $0.58 \pm 0.02$ & $0.054 \pm 0.005$ \\
\hline & & & $100+$ & $14(9)$ & $22.5 \pm 1.0$ & $0.14 \pm 0.66$ & $44.6 \pm 10.5$ & $4.3 \pm 2.9$ & $1.7 \pm 1.7$ & $0.00 \pm 0.00$ & $0.74 \pm 0.07$ & $0.026 \pm 0.016$ \\
\hline & & \multirow{2}{*}{ Yes } & $<100$ & $40(30)$ & $20.2 \pm 0.8$ & $-0.56 \pm 0.56$ & $27.5 \pm 4.3$ & $-9.3 \pm 3.2$ & $3.0 \pm 1.1$ & $2.56 \pm 1.44$ & $0.62 \pm 0.03$ & $-0.105 \pm 0.027$ \\
\hline & & & $100+$ & $2(2)$ & $22.3 \pm 0.2$ & $0.73 \pm 6.82$ & $37.2 \pm 7.4$ & $-19.2 \pm 19.2$ & $0.0 \pm 0.0$ & $0.00 \pm 0.00$ & $0.68 \pm 0.08$ & $-0.533 \pm 0.150$ \\
\hline & & \multirow{3}{*}{ All } & $<100$ & 302 (217) & $19.3 \pm 0.4$ & $0.18 \pm 0.20$ & $21.7 \pm 1.7$ & $1.7 \pm 0.7$ & $2.7 \pm 0.5$ & $0.78 \pm 0.39$ & $0.58 \pm 0.02$ & $0.033 \pm 0.006$ \\
\hline & & & $100+$ & $16(11)$ & $22.4 \pm 0.9$ & $0.21 \pm 0.85$ & $43.7 \pm 9.2$ & $1.3 \pm 3.7$ & $1.4 \pm 1.4$ & $0.00 \pm 0.00$ & $0.73 \pm 0.06$ & $-0.044 \pm 0.052$ \\
\hline & & & All & $318(228)$ & $19.4 \pm 0.4$ & $0.18 \pm 0.19$ & $22.8 \pm 1.7$ & $1.7 \pm 0.7$ & $2.7 \pm 0.5$ & $0.74 \pm 0.37$ & $0.59 \pm 0.02$ & $0.029 \pm 0.007$ \\
\hline & \multirow{3}{*}{ Protected } & \multirow{3}{*}{ No (All) } & $<100$ & $19(12)$ & $19.7 \pm 1.0$ & $0.26 \pm 0.39$ & $32.9 \pm 7.6$ & $4.0 \pm 1.9$ & $7.4 \pm 5.0$ & $-1.99 \pm 3.53$ & $0.67 \pm 0.06$ & $0.036 \pm 0.016$ \\
\hline & & & $100+$ & $11(8)$ & $23.2 \pm 1.4$ & $0.64 \pm 0.82$ & $54.1 \pm 10.8$ & $7.7 \pm 4.6$ & $14.9 \pm 8.9$ & $0.22 \pm 2.55$ & $0.71 \pm 0.06$ & $0.016 \pm 0.022$ \\
\hline & & & All & $30(20)$ & $21.0 \pm 0.9$ & $0.40 \pm 0.38$ & $40.6 \pm 6.4$ & $5.4 \pm 2.0$ & $10.4 \pm 4.6$ & $-1.11 \pm 2.31$ & $0.68 \pm 0.04$ & $0.029 \pm 0.013$ \\
\hline \multirow{3}{*}{ All } & \multirow{3}{*}{ All } & \multirow{3}{*}{ All } & $<100$ & 3028 (2122) & $18.9 \pm 0.1$ & $0.05 \pm 0.06$ & $18.6 \pm 0.5$ & $1.8 \pm 0.2$ & $2.5 \pm 0.2$ & $-0.31 \pm 0.12$ & $0.57 \pm 0.01$ & $0.026 \pm 0.003$ \\
\hline & & & $100+$ & $261(180)$ & $22.9 \pm 0.3$ & $-0.58 \pm 0.21$ & $40.9 \pm 2.3$ & $2.3 \pm 0.9$ & $7.8 \pm 1.0$ & $-0.76 \pm 0.63$ & $0.69 \pm 0.01$ & $-0.003 \pm 0.008$ \\
\hline & & & All & $3289(2302)$ & $19.2 \pm 0.1$ & $-0.00 \pm 0.06$ & $20.4 \pm 0.5$ & $1.9 \pm 0.2$ & $2.9 \pm 0.2$ & $-0.34 \pm 0.12$ & $0.58 \pm 0.01$ & $0.023 \pm 0.002$ \\
\hline
\end{tabular}




\subsection{Silvicultural Implications}

Although much of the current interest in restoration of old-growth attributes stems from experiences in the Pacific Northwest in the 1980s (e.g., [75]), since the 1990s there has been increased attention in the Northeast, accompanied by a growing body of supporting data and practical recommendations. Keeton [16] outlined a rationale and general approach ("structural complexity enhancement," SCE) for the restoration of old-growth structural attributes within actively managed stands of the northeastern U.S., while D'Amato and Catanzaro [19] highlight specific practical issues for managers. As Franklin et al. ([68], pp. 40-402) wrote, "Foresters... will be most successful if their efforts are based on a comprehensive understanding of the structures and developmental processes in natural forest stands". Although several studies have examined old-growth structures at the stand scale, and numerous authors have commented on the rarity of old forests at the regional scale, there have been relatively few opportunities to use remeasured plots to look at developmental processes or dynamics at either scale, and to use those dynamics to address silvicultural and policy recommendations.

In terms of structure, the LS and OG plots in this study are broadly consistent with those in other recent studies in forests of similar composition the northeastern U.S. and adjacent areas of Canada that report comparable metrics [26,30,63-65,76], and in terms of averages and ranges, the LS and OG plots show consistency over time as well. These consistencies should provide some confidence in setting broad structural targets and criteria for restoration, akin to the index approach of [3]. For example, an average basal area of 30-35 m/2/ha, with a QMD between 22 and $25 \mathrm{~cm}$ for trees over $7.5 \mathrm{~cm} \mathrm{DBH}$, with a combination of at least 40 live and dead trees/ha over $40 \mathrm{~cm} \mathrm{DBH}$ (and perhaps at least 10 over $50 \mathrm{~cm}$ ) and several large downed logs/ha, seems broadly consistent with this study and others in the Northeast. We do not advocate such guidelines as management goals for all stands on all ownerships, as restoration of old-growth may be inconsistent with other legitimate management goals on both public and private land. However, they can serve as benchmarks where restoration is a goal. The suggested basal area is high in comparison to conventional silvicultural guidelines in northern hardwoods [77] and spruce-fir [78], as well as that in silvicultural trials for restoration via single-tree selection in the Lake States [79]. However, we note that the stocking levels calculated using SWARD (which adjusts for both tree size and species composition) are consistent with a position between the B-line and the A-line in the guides. However, we also note that there is considerable variability in stocking levels within the OG plots, speaking to the horizontal heterogeneity associated with old-growth conditions [68]. Including gaps that can provide for regeneration of species less shade-tolerant than Fagus seems critically important, especially given the apparent sensitivity of old-growth forest dynamics in the presence of beech bark disease.

Keeton [16] expressed concerns that a rotated-sigmoid diameter distribution, designed to allow for greater retention of large live trees by reallocating growing space from smaller trees, might be challenging if natural mortality drove stands back toward a classic exponential distribution. Although many of the OG plots in this study were aptly described by an exponential distribution at the initial measurement, some were not; and there was no overall trend at the individual plot scale toward an exponential distribution over time. Indeed, the diversity of distributions represented by LS and OG plots suggests that somewhat looser criteria can be applied, with careful marking taking precedence over strict adherence to diameter distribution goals [77]. Unimodal distributions were observed in 
some OG plots and many of the LS plots, suggesting that it may not be necessary to maintain all age and size classes of trees in an intimate mixture, which can be a potential challenge [80]. Because these LS and OG stands contain a mixture of species characterized by different shade tolerance and growth rate, there is a risk that even in a stand with an exponential or nearly exponential diameter distribution, the age distribution is similar to that which would be expected from a stratified, single-cohort mixture. Rigid application of diameter regulation at a fine scale in such stands creates the danger of what Smith ([81]; p. 287) describes as "high grading by stages." Maintenance of a high basal area uniformly throughout the stand will also tend to push regeneration toward shade-tolerant species, exacerbating the hazard from beech bark disease on many sites. Rather, viewing the diameter distribution as a broad tool for regulating volume and stocking at a larger, aggregated scale $[82,83]$, and recognizing that at a broader scale the diameter distribution is a mixture of the distributions at the scales of individual plots or immediate silvicultural neighborhoods, a rotated-sigmoid may have much to commend it as a target. Indeed, following the early work by Leak [54] and Goff and West [55], interest in rotated-sigmoid structures has become even more widespread [84-88]. Such a distribution could probably be sustained at the stand scale using group or patch selection as a regeneration method, followed by appropriate intermediate treatments to maintain timber quality while accelerating the development of large trees for both economic and ecological objectives (e.g., crown release [89]), and we believe additional research along the lines of that suggested by Keeton [16] is likely to be fruitful.

\subsection{Policy Implications}

Recent regional trends describe an abundance of old-growth structure that is nearly static, despite a nominal aging of regional forests and broad availability of general guidelines for structural enhancement. The lack of positive change is especially apparent on unprotected private forests, which represent the majority of forested lands in the region. Nearly $20 \%$ of the plots over 100 years old in the regional analysis were harvested in some manner during the five year period, and harvests were associated with reductions in both QMD and the density of large live trees, especially on private lands. We note that harvest levels of forests with LSOG attributes may vary across the region. For example, harvesting pressure may be much greater in the forests of northern Maine, where significant areas are in large private investment holdings, and lower in southern Maine where non-industrial landowners dominate [71]. Most non-industrial private forest (NIPF) owners are only somewhat motivated to harvest their forests, including LSOG stands [90]. However, the typical age of NIPF owners $(>55)$ suggests that there will soon be a widespread turnover of land to inexperienced family members who are more likely to harvest timber, potentially including stands with LSOG attributes, which represent a ready source of cash [91]. Taken as a whole, if this regional trend of systematically altering older forests continues it is unlikely LSOG structures within the future forest landscape will be much, if any, more abundant than current stocks. One policy alternative for increasing LSOG in the northeast would seem to be acquisition of additional land by the public sector, and/or additional protection for lands that are currently publically owned. Public lands protected from harvest represent only $0.9 \%$ of the total forest area and are not evenly distributed in the region. However, in the current fiscal and political climate such an alternative is probably neither desirable nor feasible. If maintaining or increasing LSOG acreage and/or structures is an important goal, it may require new policy and/or market-based 
mechanisms to mitigate recent and historical trends, particularly on private lands. These policies and/or mechanisms would need to incentivize retention of LSOG structure, facilitate the recruitment of future structures, and allow for flexible management to create climate-resilient forests.

Attempting to obligate the development of LSOG structures on private lands through regulatory means could be especially problematic. Silvicultural objectives are difficult to prescribe in a policy context and often have unintended consequences. For example, in the state of Maine where the intensive plots were located, the Maine Forest Practices Act of 1989 set limitations on clearcut harvest size and adjacency with the intent to "promote a healthy and sustainable forest that contains a balance of age classes necessary for a sustainable timber supply and spatial and compositional diversity" [92]. However, one implication of a perceived hurdle to intensive even-aged silviculture has been to disperse the harvesting activity across a greater area in Maine. In 1988, Maine forest landowners reported 101,000 ha harvested compared to an average of 197,000 ha between 1990 and 2011 [93]. Mean total annual harvest volumes have remained relatively constant over the same time period at 13.6 million green MT [71]. The implications of such extensive harvest activities reflected in our analysis as more and more of the landscape is impacted by harvesting, particularly older stands that would typically have higher merchantable volume. Though there are minor fluctuations in harvest volume over time, and there is some variation in sawlog to pulpwood ratios, total harvest remains steady particularly as energy wood (biomass) harvests increased since 2004 [93]. The increase in harvest acreage since 1988 has largely been a shift away from clearcutting to "partial" harvests and shelterwood silvicultural systems that leave a dispersed low density canopy (Figure 7). In recent years, there has been a more pronounced shift to harvests described as shelterwood, which will likely result in future losses of large tree structure as these systems are completed in an overstory removal operation to release established regeneration. The regulatory framework does not specify canopy retention requirements. Retention of larger diameter trees to meet minimum basal area requirements could partly mitigate the loss of large trees from harvested plots, as seen in Table 4. This history of harvest activity as a response to public policy illustrates the challenge of using legal frameworks to achieve complex ecological outcomes.

One regulatory arena in which maintenance or enhancement of LSOG structure could be supported is the "current use" legal framework, which provides tax incentives to private landowners who maintain and manage forests. For example, in Maine, the landowner claiming "managed forest open space land" must commission a forest management and harvest plan and update and share it with the assessor at least every 10 years [94]. However, in a key difference with the older "tree growth" option, the parcel does not have to be used for commercial forest management to be eligible for this new category. Thus, as long as some minimal level of tree cutting is called for under the forest management and harvest plan and it in fact takes place, the property should qualify as "managed forest open space land." For example, felled trees would not have to be sold or processed, and could lie fallen on the parcel in order to create wildlife habitat, restore nutrients to the soil, or foster old growth communities among the remaining standing trees. Certainly the new framework appears to allow for a broader range of silvicultural activities to meet non-market objectives than previously, though it does not dictate any particular activities that would necessarily lead to LSOG enhancement. 
Figure 7. Total forest area harvested in Maine, 1988-2011, by type of harvest.

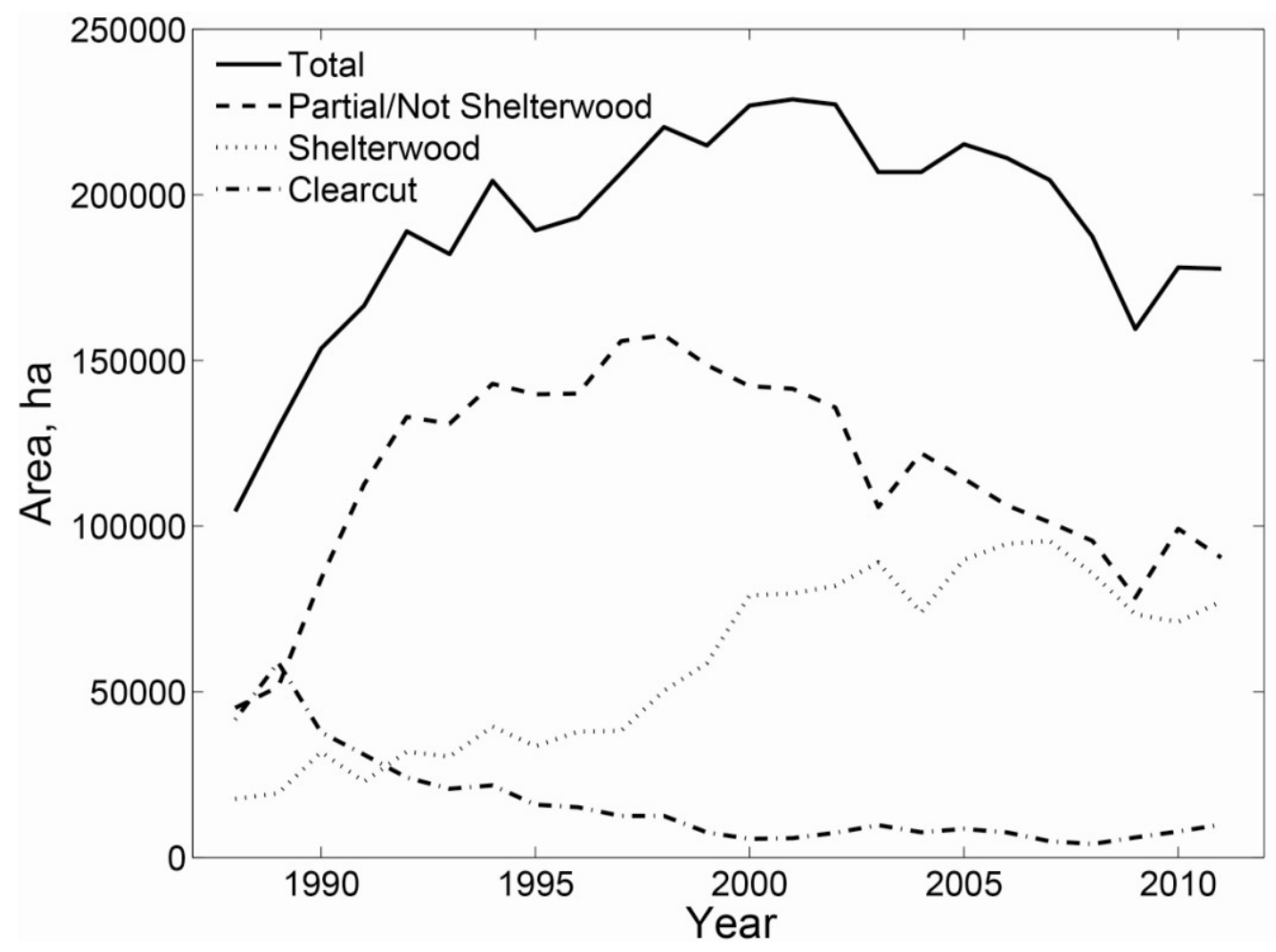

Voluntary market mechanisms such as forest certification may be more flexible than other tools to achieve standards-based outcomes when it comes to ecological patterns and processes. Increasing landowner participation in forest certification might require market demand signals from both processors and ultimately from forest stakeholders and consumers for conservation of LSOG stands and structure. Landowners in the analysis region participate in three forest certification systems: Sustainable Forestry Initiative (SFI), American Tree Farm System (ATFS), and Forest Stewardship Council (FSC) [95-97]. Standards in each system define expectations of participating landowners with respect to the wide range of forestry, ecological, economic, and social aspects of forest management. All three systems use a third-party expert auditing process within which participating landowners are required to address discrepancies when failing to conform to the standard. Each system addresses the maintenance and creation of LSOG structures differently. We studied the published standards of SFI, ATFS, and FSC applicable to the US to determine to what extent LS and OG structures and forests would be created and/or protected by participating landowners (Table 5). We reviewed the standards and asked the following questions: (1) Does the certification system require retention of forest structural attributes typical of LSOG forests (e.g., large live and dead standing trees)? (2) Does the system require conservation of LS forest? (3) Does the system address old growth forest conservation? and, Does the system require protection of existing OG forest? We then documented the language from each standard that addressed LS and OG forest structure, conservation, and protection (Table 5). 
Table 5. Comparison of standards relevant to maintenance and enhancement of late-successional and old-growth (LSOG) forests in three forest certification systems: Sustainable Forestry Initiative [95], American Tree Farm System [96], and Forest Stewardship Council [97].

\begin{tabular}{|c|c|c|c|}
\hline & \multicolumn{3}{|c|}{ Certification System Standards } \\
\hline & $\begin{array}{l}\text { SFI (Sustainable Forestry Initiative 2010-2014 } \\
\text { Standard) }\end{array}$ & $\begin{array}{c}\text { ATFS (2010-2015 } \\
\text { Standards of Sustainability } \\
\text { for Forest Certification) }\end{array}$ & FSC (FSC-US Forest Management Standard v1.0, approved 8 July 2010) \\
\hline $\begin{array}{l}\text { Does the standard require } \\
\text { retention of forest } \\
\text { structural attributes typical } \\
\text { of LSOG forests (e.g., } \\
\text { large live and dead } \\
\text { standing trees)? }\end{array}$ & Yes & No & Yes \\
\hline $\begin{array}{l}\text { Does the standard require } \\
\text { conservation of LS forest? }\end{array}$ & No & No & Yes \\
\hline $\begin{array}{l}\text { Criteria relevant to } \\
\text { conservation of LS stands } \\
\text { and forest structure }\end{array}$ & $\begin{array}{l}\text { Objective 4: Conservation of Biological Diversity } \\
\text { including } \\
\text { Forests with Exceptional Conservation Value. } \\
\text { Performance Indicator 4.1: Program Participants shall } \\
\text { have programs to promote biological diversity at stand- } \\
\text { and landscape-levels. } \\
\text { Indicator 4: Development and implementation of criteria, } \\
\text { as guided by regionally appropriate best scientific } \\
\text { information, to retain stand-level wildlife habitat } \\
\text { elements such as snags, stumps, mast trees, down woody } \\
\text { debris, den trees and nest trees. } \\
\text { Indicator 5: Program for assessment, conducted either } \\
\text { individually or collaboratively, of forest cover types, age } \\
\text { or size classes, and habitats at the individual ownership } \\
\text { level and, where credible data are available, across the } \\
\text { landscape, and take into account findings in planning and } \\
\text { management activities. }\end{array}$ & None Applicable & $\begin{array}{l}\text { Indicator 6.3.a.1: The forest owner or manager maintains, enhances, and/or } \\
\text { restores under-represented successional stages in the FMU [Forest Management } \\
\text { Unit] that would naturally occur on the types of sites found on the FMU. Where } \\
\text { old growth of different community types that would naturally occur on the } \\
\text { forest are under-represented in the landscape relative to natural conditions, a } \\
\text { portion of the forest is managed to enhance and/or restore old growth } \\
\text { characteristics. } \\
\text { Indicator 6.3.f Management maintains, enhances, or restores habitat } \\
\text { components and associated stand structures, in abundance and distribution that } \\
\text { could be expected from naturally occurring processes. These components } \\
\text { include: } \\
\text { (a) large live trees, live trees with decay or declining health, snags, and well- } \\
\text { distributed coarse down and dead woody material. Legacy trees where present } \\
\text { are not harvested; and } \\
\text { (b) vertical and horizontal complexity. } \\
\text { Trees selected for retention are generally representative of the dominant species } \\
\text { naturally found on the site. }\end{array}$ \\
\hline
\end{tabular}


Table 5. Cont.

Certification System Standards

\begin{tabular}{|c|c|c|c|}
\hline & \multicolumn{3}{|c|}{ Certification System Standards } \\
\hline & $\begin{array}{l}\text { SFI (Sustainable Forestry Initiative 2010-2014 } \\
\text { Standard) }\end{array}$ & $\begin{array}{c}\text { ATFS (2010-2015 } \\
\text { Standards of Sustainability } \\
\text { for Forest Certification) }\end{array}$ & FSC (FSC-US Forest Management Standard v1.0, approved 8 July 2010) \\
\hline $\begin{array}{l}\text { Does the standard address } \\
\text { old growth forest } \\
\text { conservation? }\end{array}$ & Yes & Yes & Yes \\
\hline $\begin{array}{l}\text { Does the standard require } \\
\text { protection of existing } \\
\text { OG forest? }\end{array}$ & No & Yes & Yes \\
\hline $\begin{array}{l}\text { Criteria relevant to } \\
\text { conservation and } \\
\text { protection of existing OG } \\
\text { forest }\end{array}$ & $\begin{array}{l}\text { Objective 4, Performance Indicator 4.1: } \\
\text { Indicator } 6 \text { : Support of and participation in plans or } \\
\text { programs for the conservation of old-growth forests in } \\
\text { the region of ownership. }\end{array}$ & $\begin{array}{l}\text { Indicator 7.1.1: Forest owner } \\
\text { must make a reasonable } \\
\text { effort to locate and protect } \\
\text { special sites appropriate for } \\
\text { the size of the forest and the } \\
\text { scale and intensity of forest } \\
\text { management activities. } \\
\text { [Special sites include "relic } \\
\text { old growth"]. }\end{array}$ & $\begin{array}{l}\text { Indicator 6.3.a.3: When they are present, management maintains the area, } \\
\text { structure, composition, and processes of all Type } 1 \text { [three acres or more that } \\
\text { have never been logged and that display old-growth characteristics] and Type } 2 \\
\text { [20 acres that have been logged, but which retain significant old-growth } \\
\text { structure and functions] old growth. Types } 1 \text { and } 2 \text { old growth are also } \\
\text { protected and buffered as necessary with conservation zones, unless an } \\
\text { alternative plan is developed that provides greater overall protection of old } \\
\text { growth values. } \\
\text { C6.4 Representative samples of existing ecosystems within the landscape shall } \\
\text { be protected in their natural state and recorded on maps, appropriate to the scale } \\
\text { and intensity of operations and the uniqueness of the affected resources. }\end{array}$ \\
\hline
\end{tabular}


Table 5. Cont.

Certification System Standards

SFI (Sustainable Forestry Initiative 2010-2014 Standard)

Criteria relevant to

conservation and

protection of existing OG

forest
Objective 4, Performance Indicator 4.1:

Indicator 6: Support of and participation in plans or

programs for the conservation of old-growth forests in

the region of ownership.
Indicator 7.1.1: Forest owner must make a reasonable effort to locate and protect special sites appropriate for the size of the forest and the scale and intensity of forest management activities.

[Special sites include "relic old growth"].

\section{FSC (FSC-US Forest Management Standard v1.0, approved 8 July 2010)}

Intent: Representative Sample Areas (RSAs) are ecologically viable representative samples designated to serve one or more of three purposes:

(1) To establish and/or maintain an ecological reference condition; or

(2) To create or maintain an under-represented ecological condition (i.e., includes samples of successional phases, forest types, ecosystems, and/or ecological communities); or

(3) To serve as a set of protected areas or refugia for species, communities and community types not captured in other Criteria of this Standard (e.g., to prevent common ecosystems or components from becoming rare).

Indicator 9.1.a: The forest owner or manager identifies and maps the presence of High Conservation Value Forests (HCVF) within the FMU and, to the extent that data are available, adjacent to their FMU, in a manner consistent with the assessment process, definitions, data sources, and other guidance described in Appendix F.

Given the relative rarity of old growth forests in the contiguous United States, these areas are normally designated as HCVF, and all old growth must be managed in conformance with Indicator 6.3.a.3 and requirements for legacy trees in Indicator 6.3.f. 
The SFI standard addresses LSOG structure in Objective 4 with a specific performance measure to promote biological diversity at stand- and landscape-levels. This performance measure includes indicators that discuss OG conservation and the stand-level retention of LSOG structure such as standing dead trees. Overall, the SFI Objective 4 specifies the "conservation of biological diversity including Forests with Exceptional Conservation Value". Though not explicitly identified, given the rarity of old-growth forests in the Northeast US, this objective could afford existing old-growth stands protection on SFI-certified lands. However, SFI does not explicitly require protection of old-growth forests on program participant lands or call for the development of LS forest structures. Standard 7 of the ATFS standard addresses the protection of "special sites", which includes "relic old-growth". The ATFS standard does not specify any other requirements related to LSOG retention and recruitment. The ATFS standard focuses on the landowner's management objectives and on having a management plan that achieves the objectives. Landowner participants in ATFS are not required to manage for LSOG structure. The FSC-US Forest Management Standard contains the most specific elements relevant to LSOG structure creation and retention. The standard explicitly addresses the maintenance and creation of under-represented forest successional stages. Based on our regional analysis, LSOG forests clearly meet this criterion and would be managed for on an FSC-certified forest. However, quantitative targets would need to be defined and justified by the manager and subject to third-party audit. The protection of existing OG forests is also explicitly addressed under Indicator 6.3.a.3 (Table 5). Guidance within Principle 9 of the FSC standard also states that "Given the relative rarity of old growth forests in the contiguous United States, these areas are normally designated as HCVF [High Conservation Value Forests], and all old growth must be managed in conformance with Indicator 6.3.a.3 and requirements for legacy trees in Indicator 6.3.f.".

Although the recruitment of additional landowners into the certification systems could improve the maintenance of LSOG stands and structure, not all certification systems are positioned to help achieve this result. The three forest certification standards address the issues of LSOG forests and/or structure but not all ensure the maintenance of these features. Only FSC requires the management to ensure a full range of age classes, including LS and protection of OG. Participating landowners in FSC certification must conserve old-growth, maintain some LS forest, and maintain LSOG attributes. Specific amounts of forest to be created or maintained would need to be based on the scale of ownership, historic range of variability, and current forest composition which would all be evaluated by a third-party auditor. The ATFS standard states that a landowner must make a "reasonable effort" to protect special sites such as relic old growth, but do not specify the creation of LS or OG structure. While protection of existing OG forest is implied under the SFI standard, the language used in the standard such as "support of and participation in plans or programs" does not explicitly require protection. The SFI standard does require the development of criteria to retain stand-level LS structure such as snags. But the requirement that an assessment of forest age and size classes on the ownership be taken into account in planning and management activities falls short of requiring the maintenance and creation of under-represented forest successional stages. Auditors of the SFI standard may interpret the language more broadly, but audit reports would need to be reviewed to determine how exactly the language is applied on the ground.

Forest carbon offset markets offer another non-regulatory mechanism to protect existing old-growth and encourage the development of more structurally-complex forests on private ownerships. A forest 
carbon assessment of the intensive plot data show that LSOG forests can store 2.0-2.5 times the regional mean and in the case of late-successional stands continue to accumulate carbon [42]. Determination of eligible volumes of carbon credits depends upon the forest carbon offset standard used [98], but generally a forest management regime that uses low-intensity harvesting and retains forest structure will compare favorably with baselines used in current forest carbon offset standards [99-101]. With both regulatory and voluntary markets for carbon offsets now functioning, forests landowners are beginning to participate in this marketplace when the revenue potential is favorable relative to the transaction and opportunity costs. Regardless, there is the potential for significant overlap in terms of using a payment for ecosystem services framework designed to achieve additional carbon storage to facilitate the development of late-successional and old-growth forest structure as co-benefits to carbon.

Finally, conservation easements have been used increasingly within the region over the last 20 years to achieve various conservation outcomes [102]. Conservation easements are legal deed restrictions attached to parcels prohibiting certain activities such as development or timber harvesting and must be monitored by the easement holder, often a private non-governmental organization or a public agency. Conservation easements are either purchased with public or private funds, or donated by a landowner that may receive tax benefits in return for the contribution and the public benefits it provides. LSOG stands and attributes can be created and protected under "forever wild" easements that prohibit timber harvesting, but such easements are less likely to receive public funding. "Working Forest" conservation easements allow forest management activity but often include requirements that a landowner follow an approved management plan [103] and/or third-party certification of their land. Such easements rely on the management planning process and forest certification standards to define managed forest outcomes and do not necessarily allow a more prescriptive approach necessary to promote LSOG structure and stand development actively. The monitoring of such easements could also be cost prohibitive given a likely need for inventories that measured quantitative objectives and/or verified that management activities designed to maintain, enhance, and restore LSOG structures were actually carried out. Given this complexity, the most likely use of conservation easements for LSOG development would be a "forever wild" context where timber harvesting is excluded as a legal land use. However, with additional development of appropriate legal language for the easements themselves, design of management approaches that preserved landowner flexibility while achieving LSOG restoration objectives, and cost-effective approaches for monitoring and verification, conservation easements could hold promise for more active restoration of LSOG structure.

\section{Conclusions}

Analysis of the changes on permanent plots in LS and OG forests in Maine shows that the structure of LSOG stands is dynamic, showing an influence both of endogenous development and of the impacts of beech bark disease. Although aspects of LSOG forest structure, including large QMD, elevated abundance of large live trees, and the presence of large standing and downed dead trees were maintained at levels consistent with those previously reported for studies of LSOG forests in the region that used temporary plots, there was substantial between-plot variability. LS plots showed diameter distributions and size-density trajectories that were consistent with stem exclusion and self-thinning at the plot scale, though we caution that at larger scales (including the stand as a whole) a mixture of such 
patches might "average out" to give a slightly different set of distributions and apparent dynamics. The OG plots, which included the heaviest stocking of Fagus, were the most heavily impacted by beech bark disease and showed dynamics much more consistent with a transition to density-independent mortality (e.g., [68]). However, there was no trend toward a classic "balanced" exponential distribution. Taken together, the diversity of structures and dynamics seen on these plots suggest that it may be fruitful to consider the enhancement of LS and OG structural characteristics in stands that likewise display a diversity of structures and dynamics. In particular, there seems to be little need to attempt to enforce an intimate and uniform mixture of size and age classes using single-tree selection. We hope that this will liberate creative silviculturists in considering alternatives for increasing LS and OG structure within the context of other silvicultural systems.

Examining the regional situation, however, the picture is less optimistic. Although the concepts, values, and basic techniques associated with LS and OG restoration have been circulating broadly in the forestry community for over two decades, and regional stand age distributions suggest large areas poised to enter into LSOG status, QMD is static, numbers of large live trees are only weakly increasing, and numbers of large standing dead trees are slightly declining. A strong tendency for increase in these structural measures in protected forests, and a weaker one in unprotected forests that have not been harvested, has been nearly offset by substantial reductions on plots that have experienced harvest. With nearly $20 \%$ of the forested area, including older stands, experiencing harvest in a 5-year period, it seems realistic to expect LSOG structural attributes to approach a sort of dynamic equilibrium in unprotected forests, and LSOG restoration will remain an important conservation priority over the coming decades despite the apparent aging of the regional forest. Voluntary and market-based strategies, including wider participation in forest certification programs and close attention to existing standards in those programs that support maintenance and enhancement of LSOG structures, and the emerging opportunities associated with forest carbon offset markets, provide some hope for incentives that could help stimulate broader LSOG restoration efforts.

\section{Acknowledgments}

Funding for this research was provided by the New Hampshire Agricultural Experiment Station, USDA Northeastern States Research Cooperative, the Cooperative Forestry Research Unit at the University of Maine, Davis Conservation Foundation, the National Fish and Wildlife Foundation, the Maine Outdoor Heritage Fund, The Emily V. Wade Fund for Science, Fox Family Foundation, and Manomet Center for Conservation Sciences. We would like to thank the 2011 Field Crew (Jordan Bowmerman and Kathleen McKeever), all the previous field crews (1995-2002), 1995-2000 crew leader Stacie Grove, and Felicia Hatch who assisted with GIS analysis. We thank the Maine Chapter of The Nature Conservancy for permission to conduct this work in the Big Reed Forest Reserve and Plum Creek for permission to work on their private land in Kibby and Skinner Townships of Maine.

\section{Conflicts of Interest}

John Gunn has served on the Forest Stewardship Council (FSC) US Board of Directors from 2010-2013. The authors declare no other conflict of interest. 


\section{References}

1. Harmon, M.E.; Ferrell, W.K.; Franklin, J.F. Effects on carbon storage of conversion of old-growth forests to young forests. Science 1990, 247, 699-702.

2. Luyssaert, S.; Schulze, E.; Börner, A. Old-growth forests as global carbon sinks. Nature 2008, $455,213-215$.

3. Whitman, A.A.; Hagan, J.M. An index to identify late-successional forest in temperate and boreal zones. For. Ecol. Manag. 2007, 246, 144-154.

4. Reed, W.J. The decision to conserve or harvest old-growth forest. Ecol. Econ. 1993, 8, 45-69.

5. Freedman, B.; Zelazny, V.; Beaudette, D.; Fleming, T.; Fleming, S.; Forbes, G.; Gerrow, J.; Johnson, G.; Woodley, S. Biodiversity implications of changes in quantity of dead organic matter in managed forests. Environ. Rev. 1996, 4, 238-265.

6. Recher, H. Conservation and Management of Eucalypt Forest Vertebrates. In Conservation of Faunal Diversity in Forested Landscapes; DeGraaf, R.M., Miller, R.I., Eds.; Chapman and Hall: New York, NY, USA, 1996; pp. 339-388.

7. Lindenmayer, D.B.; Franklin, J.F. Conserving Forest Biodiversity: A Comprehensive Multiscaled Approach; Island Press: Washington, DC, USA, 2002.

8. Irland, L.C. The Northeast's Changing Forests; Harvard University Press: Cambridge, MA, USA, 1999.

9. Foster, D.R. Forests in Time: The Environmental Consequences of 1,000 Years of Change in New England; Yale University Press: New Haven, CT, USA, 2006.

10. Pan, Y.; Chen, J.-M.; Birdsey, R.; McCullough, K.; He, L.; Deng, F. Age structure and disturbance legacy of North American forests. Biogeosciences 2011, 8, 715-732.

11. Lorimer, C.G. The Presettlement forest and natural disturbance cycle of northeastern maine. Ecology 1977, 58,139-148.

12. Cogbill, C.V. Vegetation of the presettlement forests of northern New England and New York. Rhodora 2000, 102, 250-276.

13. Lorimer, C.G. Historical and ecological roles of disturbance in eastern North American forests: 9,000 years of change. Wildl. Soc. Bull. 2001, 29, 425-439.

14. Lorimer, C.G.; White, A.S. Scale and frequency of natural disturbances in the northeastern U.S.: Implications for early-successional forest habitats and regional age distributions. For. Ecol. Manag. 2003, 185, 41-64.

15. Davis, M.B. Eastern old-Growth Forests: Prospects for Rediscovery and Recovery; Island Press: Covelo, CA, USA, 1996.

16. Keeton, W.S. Managing for late-successional/old-growth characteristics in northern hardwood-conifer forests. For. Ecol. Manag. 2006, 235, 129-142.

17. North, M.P.; Keeton, W.S. Emulating Natural Disturbance Regimes: An Emerging Approach for Sustainable Forest Management. Chapter 17. In Patterns and Processes in Forest Landscapes; Lafortezza, R., Sanesi, G., Chen, J., Eds.; Springer Netherlands: Houten, The Netherlands, 2008; pp. 341-372.

18. Bauhus, J.; Puettmann, K.; Messier, C. Silviculture for old-growth attributes. For. Ecol. Manag. 2009, 258, 525-537. 
19. D’Amato, A.W.; Catanzaro, P.C. Restoring Old-Growth Characteristics. In Cooperative Extension Landowner Outreach Pamphlet; University of Massachusetts: Amherst, MA, USA, 2007; p. 18.

20. Burrascano, S.; Keeton, W.S.; Sabatini, F.M.; Blasi, C. Commonality and variability in the structural attributes of moist temperate old-growth forests: A global review. For. Ecol. Manag. 2013, 291, 458-479.

21. Gore, J.A.; Patterson, W.A., III. Mass of downed wood in northern hardwood forests in New Hampshire: Potential effects of forest management. Can. J. For. Res. 1986, 16, 335-339.

22. Leak, W.B. Characteristics of Five Climax Stands in New Hampshire; Research Note NE-336; USDA Forest Service, Northeastern Forest Experiment Station: Broomall, PA, USA, 1987.

23. Odum, E.P. The strategy of ecosystem development. Science 1969, 164, 262-270.

24. Jarvis, P.G. Atmospheric carbon dioxide and forests. Philos. Trans. R. Soc. Biol. Sci.1989, 324, 369-392.

25. Keith, H.; Mackey, B.G.; Lindenmayer, D.B. Re-evaluation of forest biomass carbon stocks and lessons from the world's most carbon-dense forests. Proc. Natl. Acad. Sci. USA 2009, 106, 11635-11640.

26. Keeton, W.; Whitman, A.; McGee, G.G.; Goodale, C.L. Late-successional biomass development in northern hardwood-conifer forests of the northeastern United States. For. Sci. 2011, 57, 489-505.

27. Galik, C.S.; Jackson, R.B. Risks to forest carbon offset projects in a changing climate. For. Ecol. Manag. 2009, 257, 2209-2216.

28. Hurteau, M.D.; Hungate, B.A.; Koch, G.W. Accounting for risk in valuing forest carbon offsets. Carbon Balanc. Manag. 2009, 4, 1-5.

29. Tyrrell, L.E.; Crow, T.R. Structural characteristics of old-growth hemlock-hardwood forests in relation to age. Ecology 1994, 75, 370-386.

30. McGee, G.G.; Leopold, D.J.; Nyland, R.D. Structural characteristics of old-growth, maturing, and partially cut northern hardwood forests. Ecol. Appl. 1999, 9, 1316-1329.

31. Henry, J.D.; Swan, J.M.A. Reconstructing forest history from live and dead plant material--an approach to the study of forest succession in southwest New Hampshire. Ecology 1974, 55, 772-783.

32. Ziegler, S.S. Composition, structure, and disturbance history of old-growth and second-growth forests in Adirondack Park, New York. Phys. Geogr. 2004, 25, 152-169.

33. D'Amato, A.W.; Orwig, D.A.; Foster, D.R. The influence of successional processes and disturbance on the structure of Tsuga canadensis forests. Ecol. Appl. 2004, 18, 1182-1199.

34. Foster, D.R. Disturbance history, community organization and vegetation dynamics of the old-growth Pisgah Forest, southwestern New Hampshire, USA. J. Ecol. 1988, 76, 105-134.

35. Filip, S.M.; Marquis, D.A.; Leak, W.B. Development of Old-Growth Northern Hardwoods on Bartlett Experimental Forest-A 22-Year Record; U.S. Forest Service, Northeastern Forest Experiment Station Paper 135; U.S. Forest Service: Washington, DC, USA, 1960.

36. Woods, K.D. Dynamics in late-successional hemlock-hardwood forests over three decades. Ecology 2000, 81, 110-126. 
37. Woods, K.D. Long-term change and spatial pattern in a late-successional hemlock-northern hardwood forest. J. Ecol. 2000, 88, 267-282.

38. Lorimer, C.G.; Dahir, S.E.; Nordheim, E.V. Tree mortality rates and longevity in mature and old-growth hemlock-hardwood forests. J. Ecol.2001, 89, 960-971.

39. Busing, R.T. Tree mortality, canopy turnover, and woody detritus in old cove forests of the southern Appalachians. Ecology 2005, 86, 73-84.

40. Hagan, J.M.; Grove, S.L. Coarse woody debris: Humans and nature competing for trees. J. For. 1999, 97, 6-11.

41. Gunn, J.S.; Hagan, J.M. Woodpecker abundance and tree use in uneven-aged managed, and unmanaged, forest in northern Maine. For. Ecol. Manag. 2000, 126, 1-12.

42. Gunn, J.S.; Ducey, M.J.; Whitman, A.A. Late-successional and old-growth forest carbon temporal dynamics in the northern forest (northeastern USA). For. Ecol. Manag. 2013, in press.

43. Whitman, A. Manomet Center for Conservation Sciences: Brunswick, ME, USA. Unpublished Data, 2013.

44. Fraver, S.; White, A.S.; Seymour, R.S. Natural disturbance in an old-growth landscape of northern Maine, USA. J. Ecol. 2009, 97, 289-298.

45. Tyrrell, L.E.; Nowacki, G.J.; Crow, T.R.; Buckley, D.S.; Nauertz, E.A.; Niese, J.N.; Rollinger, J.L.; Zasada, J.C. Information about Old Growth for Selected Forest Type Groups in the Eastern United States; General Technical Report NC-197; USDA Forest Service, North Central Forest Experiment Station: St. Paul, MN, USA, 1998.

46. Gove, J.H.; van Deusen, P.C. On fixed-area plot sampling for downed coarse woody debris. Forestry 2011, 84, 109-117.

47. Reineke, L.H. Perfecting a stand-density index for even-aged forests. J. Agric. Res. 1933, 46, 627-638.

48. Ducey, M.J.; Knapp, R.A. A stand density index for complex mixed species forests in the northeastern United States. For. Ecol. Manag. 2010, 260, 1613-1622.

49. Gingrich, S.F. Measuring and evaluating stocking and stand density in upland hardwood forests in the Central States. For. Sci. 1967, 13, 38-53.

50. Meyer, H.A.; Stevenson, D.D. The structure and growth of virgin beech-birch-maple-hemlock forests in northern Pennsylvania. J. Agric. Res. 1943, 67, 465-484.

51. Meyer, H.A. Structure, growth, and drain in uneven-aged forests. J. For. 1952, 50, 85-92.

52. De Liocourt, F. De l'amanagement des sapinieres. In Bulletin Trimestriel; Société forestière de Franche-Comté et Belfort, Ed.; Impr. et litographie de Paul Jacquin: Besancon, France, 1898 (in French).

53. Leak, W.B. The $J$-shaped probability distribution. For. Sci.1965, 11, 405-409.

54. Leak, W.B. An expression of diameter distribution for unbalanced, uneven-aged stands and forests. For. Sci. 1964, 10, 39-50.

55. Goff, F.G.; West, D. Canopy-understory interaction effects on forest population structure. For. Sci. 1975, 21, 98-108.

56. Bailey, R.L.; Dell, T.R. Quantifying diameter distributions with the Weibull function. For. Sci. 1973, 19, 97-104.

57. Stacy, E.W. A generalization of the gamma distribution. Ann. Math. Stat. 1962, 33, 1187-1192. 
58. McDonald, J.B. Some generalized functions for the size distribution of income. Econometrica 1984, 52, 647-664.

59. Akaike, H. A new look at the statistical model identification. IEEE Trans. Autom. Control 1974, 19, 716-723.

60. Burnham, K.P.; Anderson, D.R. Model Selection and Multimodel Inference: A Practical Information-Theoretic Approach, 2nd ed.; Springer-Verlag: New York, NY, USA, 2002.

61. The Enhanced Forest Inventory and Analysis Program-National Sampling Design and Estimation Procedures; General Technical Report SRS-80; Bechtold, W.A., Patterson, P.L., Eds.; USDA Forest Service, Southern Research Station: Asheville, NC, USA, 2005.

62. R Core Team. R: A Language and Environment for Statistical Computing; R Foundation for Statistical Computing: Vienna, Austria, 2012.

63. Beaudet, M.; Brisson, J.; Gravel, D.; Messier, C. Effect of a major canopy disturbance on the coexistence of Acer saccharum and Fagus grandifolia in the understorey of an old-growth forest. J. Ecol. 2007, 95, 458-467.

64. Keeton, W.S.; Kraft, C.E.; Warren, D.R. Mature and old-growth riparian forests: Structure, dynamics, and effects on Adirondack stream habitats. Ecol. Appl. 2007, 17, 852-868.

65. Hoover, C.M.; Leak, W.B.; Keel, B.G. Benchmark carbon stocks from old-growth forests in northern New England, USA. For. Ecol. Manag. 2012, 266, 108-114.

66. McGarrigle, E.; Kershaw, J.A.; Ducey, M.J.; Lavigne, M.B. A new approach to modeling stand-level dynamics based on informed random walks: Influence of bandwidth and sample size. Forestry 2013, 86, 377-389.

67. Oliver, C.D.; Larson, B.C. Forest Stand Dynamics; Wiley: New York, NY, USA, 1996.

68. Franklin, J.F.; Spies, T.A.; van Pelt, R.; Carey, A.; Thornburgh, D.; Berg, D.R.; Lindenmayer, D.; Harmon, M.; Keeton, W.S.; Shaw, D.C.; et al. Disturbances and the structural development of natural forest ecosystems with some implications for silviculture. For. Ecol. Manag. 2002, 155, 399-423.

69. Morin, R.S.; Liebhold, A.M.; Tobin, P.C.; Gottschalk, K.W.; Luzader, E. Spread of beech bark disease in the eastern United States and its relationship to regional forest composition. Can. J. For. Res. 2007, 37, 726-736.

70. Kasson, M.T.; Livingston, W.H. Relationships among beech bark disease, climate, radial growth response and mortality of American beech in northern Maine, USA. For. Pathol. 2012, 42, 199-212.

71. McCaskill, G.L.; McWilliams, W.H.; Barnett, C.J.; Butler, B.J.; Hatfield, M.A.; Kurtz, C.M.; Morin, R.S.; Moser, W.K.; Perry, C.H.; Woodall, C.W. Maine's Forests 2008; Resource Bulletin No. NRS-48; USDA Forest Service, Northern Research Station: Newtown Square, PA, USA, 2011.

72. Canham, C.D.; Rogers, N.; Buchholz, T. Regional variation in forest harvest regimes in the northeastern United States. Ecol. Appl. 2013, 23, 515-522.

73. Zheng, D.L.; Heath, L.S.; Ducey, M.J.; Butler, B. Relationships between ownership, forest aboveground biomass distributions and landscape dynamics in the New England states of USA. Environ. Manag. 2010, 45, 377-386.

74. Benjamin, J.; Lilieholm, R.J.; Damery, D. Challenges and opportunities for the northeastern forest bioindustry. J. For. 2009, 107, 125-131. 
75. Franklin, J.F. Toward a new forestry. Am. For. 1989, 95, 37-44.

76. Orwig, D.A.; Cogbill, C.V.; Foster, D.R.; O'Keefe, J.F. Variations in old-growth structure and definitions: Forest dynamics on Wachusett Mountain, Massachusetts. Ecol. Appl. 2001, 11, 437-452.

77. Leak, W.B.; Solomon, D.S.; de Bald, P.S. Silvicultural Guide to Northern Hardwood Types in the Northeast, Revised; Research Paper NE-603; USDA Forest Service, Northeastern Forest Research Station: Broomall, PA, USA, 1987.

78. Frank, R.M.; Bjorkbom, J.C. A Silvicultural Guide for Spruce-Fir in the Northeast; General Technical Report NE-6; USDA Forest Service, Northeastern Forest Research Station: Upper Darby, PA, USA, 1973.

79. Gronewald, C.A.; D'Amato, A.W.; Palik, B.J. The influence of cutting cycle and stocking level on the structure and composition of managed old-growth northern hardwoods. For. Ecol. Manag. 2010, 259, 1151-1160.

80. Smith, D.M.; Larson, B.C.; Kelty, M.J.; Ashton, P.M.S. The Practice of Silviculture: Applied Forest Ecology, 9th ed.; John Wiley and Sons: New York, NY, USA, 2007.

81. Smith, D.M. Concluding Remarks. In The Ecology and Silviculture of Mixed-Species Forests; Kelty, M.J., Oliver, C.D., Larson, B.C., Eds.; Kluwer Academic Publishers: Dordrecht, The Netherlands, 1992; pp. 281-287.

82. O'Hara, K.L.; Gersonde, R.F. Stocking control concepts in uneven-aged silviculture. Forestry 2004, 77, 131-143.

83. Ducey, M.J. The Reverse-J and Beyond: Developing Practical, Effective Marking Guides. In Proceedings of Implementing Uneven-Aged Management in New England: Is It Practical? Fox Research and Demonstration Forest, Hillsborough, NH, USA, 13 April 2006; Caroline, A., Ed.; U.N.H. Cooperative Extension: Durham, NH, USA, 2006. Available online: http://extension.unh. edu/resources/files/Resource002220_Rep3279.pdf (accessed on 1 October 2013).

84. Goodburn, J.M.; Lorimer, C.G. Population structure in old-growth and managed northern hardwoods: An examination of the balanced diameter distribution concept. For. Ecol. Manag. 1999, 118, 11-29.

85. Rouvinen, S.; Kuuluvainen, T. Tree diameter distributions in natural and managed old Pinus sylvestris-dominated forests. For. Ecol. Manag. 1995, 208, 45-61.

86. Schütz, J.P. Modelling the demographic sustainability of pure beech plenter forests in Eastern Germany. Ann. For. Sci. 2006, 63, 93-100.

87. Gove, J.H.; Ducey, M.J.; Leak, W.B.; Zhang, L. Rotated sigmoid structures in managed uneven-aged northern hardwood stands: A look at the Burr Type III distribution. Forestry 2008, 81, 161-176.

88. Allesandrini, A.; Biondi, F.; di Fillippo, A.; Ziaco, E.; Piovesan, G. Tree size distribution at increase spatial scales converges to the rotated sigmoid curve in two old-growth beech stands of the Italian Apennines. For. Ecol. Manag. 2011, 262, 1950-1962.

89. Singer, M.T.; Lorimer, C.G. Crown release as a potential old-growth restoration approach in northern hardwoods. Can. J. For. Res. 1997, 27, 1222-1232.

90. Ma, Z.; Kittredge, D.B. How family forest owners consider timber harvesting, land sale, and conservation easement decisions: Insights from Massachusetts, USA. Int. J. For. Res. 2011, $2011,1-13$. 
91. Majumdar, I.; Laband, D.; Teeter, L.; Butler, B.J. Motivations and land-use intentions of nonindustrial private forest landowners: Comparing inheritors to noninheritors. For Sci. 2009, $55,423-432$.

92. Maine Forest Practices Act, 29 July 2004. Available online: http://www.maine.gov/doc/mfs/ pubs/htm/fpa_04.html (accessed on 26 June 2013).

93. State of Maine, Department of Conservation, Maine Forest Service Silvicultural Activities Reports 1996-2011. Available online: http://www.maine.gov/doc/mfs/pubs.htm (accessed on 26 June 2013).

94. State of Maine, 2012. An Act to Amend the Maine Tree Growth Tax Law and the Open Space Tax Law. Public Law Chapter 618, H.P. 844-L.D. 1138. Available online: http://www. mainelegislature.org/legis/bills/getPDF.asp?paper=HP0844\&item=4\&snum=125 (accessed on 29 June 2013).

95. Sustainable Forestry Initiative 2010-2014 Standard. Available online: http://www.sfiprogram. org/files/pdf/section2sfirequirements2010-2014pdf/ (accessed on 26 June 2013).

96. American Forest Foundation 2010-2015 Standards of Sustainability for Forest Certification. Available online: http://www.treefarmsystem.org/certification-american-tree-farm-standards (accessed on 26 June 2013).

97. FSC-US Forest Management Standard, Ver. 1.0. Available online: http://us.fsc.org/download. fsc-us-forest-management-standard-v1-0.95.pdf (accessed on 27 June 2013).

98. Gunn, J.S.; Saah, D.S.; Fernholz, K.; Ganz, D.J. Carbon credit eligibility under area regulation of harvest levels in Northern Minnesota. For. Sci. 2011, 57, 470-478.

99. Nunery, J.S.; Keeton, W.S. Forest carbon storage in the northeastern United States: Net effects of harvesting frequency, post-harvest retention, and wood products. For. Ecol. Manag. 2010, 259, 1363-1375.

100. Climate Action Reserve Forest Project Protocol Version 3.2. Available online: http://www. climateactionreserve.org/how/protocols/forest/dev/version-3-2/ (accessed on 27 June 2013).

101. American Carbon Registry Forest Carbon Project Standard v2.1. Available online: http:// americancarbonregistry.org/carbon-accounting/carbon-accounting/forest-carbon-project-standard -v2.0 (accessed on 27 June 2013).

102. Fishburn, I.S.; Kareiva, P.; Gaston, K.J.; Armsworth, P.R. The growth of easements as a conservation tool. PLoS One 2009, 4, e4996.

103. Rissman, A.R.; Lozier, L.; Comendant, T.; Kareiva, P.; Kiesecker, J.M.; Shaw, M.R.; Merenlender, A.M. Conservation easements: Biodiversity protection and private use. Conserv. Biol. 2007, 21, 709-718.

(C) 2013 by the authors; licensee MDPI, Basel, Switzerland. This article is an open access article distributed under the terms and conditions of the Creative Commons Attribution license (http://creativecommons.org/licenses/by/3.0/). 